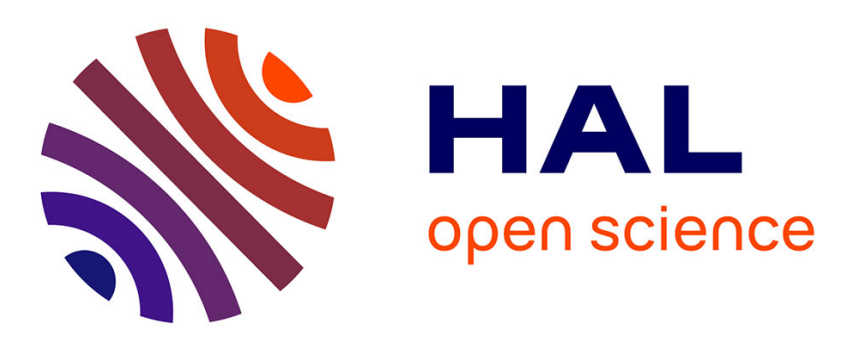

\title{
Effect of varying conditions of exposure to an aggressive medium on the corrosion behavior of the $2050 \mathrm{Al}-\mathrm{Cu}-\mathrm{Li}$ alloy
}

Mathilde Guérin, Eric Andrieu, Grégory Odemer, Joël Alexis, Christine Blanc

\section{- To cite this version:}

Mathilde Guérin, Eric Andrieu, Grégory Odemer, Joël Alexis, Christine Blanc. Effect of varying conditions of exposure to an aggressive medium on the corrosion behavior of the $2050 \mathrm{Al}-\mathrm{Cu}-\mathrm{Li}$ alloy. Corrosion Science, 2014, vol. 85, pp. 455-470. 10.1016/j.corsci.2014.04.042 . hal-01024706

\section{HAL Id: hal-01024706 https://hal.science/hal-01024706}

Submitted on 16 Jul 2014

HAL is a multi-disciplinary open access archive for the deposit and dissemination of scientific research documents, whether they are published or not. The documents may come from teaching and research institutions in France or abroad, or from public or private research centers.
L'archive ouverte pluridisciplinaire HAL, est destinée au dépôt et à la diffusion de documents scientifiques de niveau recherche, publiés ou non, émanant des établissements d'enseignement et de recherche français ou étrangers, des laboratoires publics ou privés. 


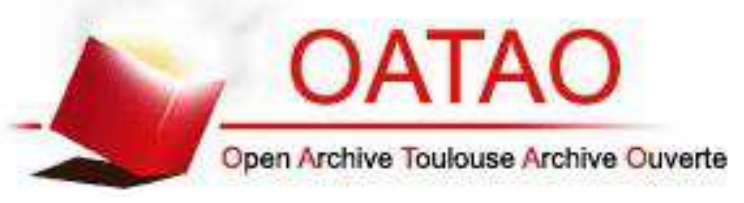

Open Archive Toulouse Archive Ouverte (OATAO)

OATAO is an open access repository that collects the work of Toulouse researchers and makes it freely available over the web where possible.

This is an author-deposited version published in: http://oatao.univ-toulouse.fr/ Eprints ID: 11782

Identification number: DOI : 10.1016/j.corsci.2014.04.042

fficial URL: http://dx.doi.org/10.1016/j.corsci.2014.04.042

\section{To cite this version:}

Guérin, Mathilde and Andrieu, Eric and Odemer, Grégory and Alexis, Joël and Blanc, Christine Effect of varying conditions of exposure to an aggressive medium on the corrosion behavior of the $2050 \mathrm{Al}-\mathrm{-Cu}-\mathrm{Li}$ alloy. (2014) Corrosion Science, vol. 85 . pp. 455-470. ISSN 0010-938X

Any correspondence concerning this service should be sent to the repository administrator: staff-oatao@inp-toulouse.fr 


\title{
Effect of varying conditions of exposure to an aggressive medium on the corrosion behavior of the $2050 \mathrm{Al}-\mathrm{Cu}-\mathrm{Li}$ alloy
}

\author{
Mathilde Guérin ${ }^{\mathrm{a}, \mathrm{b}}$, Eric Andrieu ${ }^{\mathrm{a}}$, Grégory Odemer ${ }^{\mathrm{a}}$, Joël Alexis ${ }^{\mathrm{b}}$, Christine Blanc ${ }^{\mathrm{a}, *}$ \\ ${ }^{a}$ Université de Toulouse, Institut CARNOT CIRIMAT, UPS/CNRS/INPT, ENSIACET, 4 allée Emile Monso, 31030 Toulouse Cedex 04, France \\ ${ }^{\mathrm{b}}$ Université de Toulouse, LGP, ENIT/INPT, 47 Avenue d'Azereix, 65016 Tarbes, France
}

\begin{abstract}
A B S T R A C T
The corrosion behavior of aluminum alloy 2050 was studied as a function of varying conditions of exposure to an aqueous $\mathrm{NaCl}$ solution. Two metallurgical states were considered, i.e., an as-received alloy (NHT) and aged samples (HT). After continuous immersion tests, the NHT samples were susceptible to intergranular corrosion, whereas intragranular corrosion was observed for the HT samples. For the NHT samples, cyclic corrosion tests, with alternate immersion - emersion periods, induced subgrain boundary dissolution, and for the HT samples, grain and/or subgrain boundary sensibilization was induced. Hydrogen content measurements suggested a hydrogen enrichment of the alloy under cyclic corrosion tests.
\end{abstract}

Keywords:

A. Aluminum

A. Intermetallics

B. EIS

C. Intergranular corrosion

C. Hydrogen embrittlement

\section{Introduction}

Corrosion is considered a major threat to the structural integrity of aircraft structures and may significantly reduce the lifetime of such structures. To improve the corrosion resistance of aircraft metallic structures and to reduce their weight, new aluminum alloys, called 3rd generation aluminum-copper-lithium alloys, were developed. The 2050 alloy is one of the most promising solutions because this material combines low density, good mechanical properties and good corrosion resistance. Indeed, the addition of $\mathrm{Li}$ results in the reduction of the weight of the alloy because the density is reduced by $3 \%$ for each $1 \mathrm{wt} \% \mathrm{Li}$ added to $\mathrm{Al}$, whereas the elastic modulus is increased by almost 6\% [1-3]. However, the presence of copper-rich second phases can produce micro-galvanic coupling, which leads to a decrease of the corrosion resistance of the alloy.

Previous studies focused on the corrosion behavior of $\mathrm{Al}-\mathrm{Cu}-\mathrm{Li}$ alloys demonstrated that these alloys were susceptible to different types of corrosion according to the thermomechanical treatments applied [4-8]. Thus, depending on their thermomechanical history, the $\mathrm{Al}-\mathrm{Cu}-\mathrm{Li}$ alloys may be susceptible to pitting and to intragranular or intergranular corrosion in relation to the distribution and to the type of intermetallic precipitates or dispersoids controlling the

\footnotetext{
* Corresponding author. Address: Université de Toulouse, CIRIMAT, UPS/CNRS/ INPT, 4 allée Emile Monso, BP 44362, 31030 Toulouse Cedex 4, France. Tel.: +33 (0)5 343234 07; fax: +33 (0)534323498.

E-mail address: christine.blanc@ensiacet.fr (C. Blanc).
}

local electrochemical potentials. Galvanic coupling, which occurs between second phases, usually rich in copper, and the matrix is a common mechanism responsible for pitting [9-12]. As an example, $\mathrm{Al}-\mathrm{Cu}-\mathrm{Fe}-\mathrm{Mn}$ intermetallic particles, which are encountered in $\mathrm{Al}-\mathrm{Cu}-\mathrm{Li}$ alloys, cause the dissolution of the surrounding matrix because of their nobler electrochemical potential. The effect of the precipitation of hardening phases in $\mathrm{Al}-\mathrm{Cu}-\mathrm{Li}$ alloys on their corrosion behavior has also been thoroughly studied [4,9,13-16]. The results of these studies indicated that the electrochemical potential of $\mathrm{T}_{1}-\mathrm{Al}_{2} \mathrm{CuLi}$ precipitates, which are the most common hardening precipitates encountered in these alloys, differed from that of the matrix, leading to a galvanic coupling phenomenon. For a low immersion time in chloride media, the corrosion potential of $\mathrm{T}_{1}$ precipitates was found to be more cathodic than that of the matrix, whereas for a longer immersion time, the corrosion potential of $\mathrm{T}_{1}$ precipitates evolves, as well as that of the matrix, leading to an inversion in polarity [14]. The coupling between $T_{1}$ phases and the matrix was then primarily considered responsible for the corrosion susceptibility of $\mathrm{Al}-\mathrm{Cu}-\mathrm{Li}$ alloys, with intergranular and/or intragranular corrosion, depending on the thermomechanical treatment applied to the material [7]. Furthermore, Smith and Scully proposed that hydrogen could be trapped at the incoherent interfaces of $T_{1}$ particles [17,18]; these authors considered that $T_{1}$ particles are likely to be one of the high-energy trapping states in $\mathrm{Al}-\mathrm{Li}-\mathrm{Cu}-\mathrm{Zr}$ alloys and pointed out the error in assuming that hydrogen cannot play a major role in cracking of Al-based alloys due to the low lattice solubility. Therefore, it was of interest to consider the hydrogen $-T_{1}$ particles interactions to explain the 
properties of corroded samples when hydrogen was produced during the corrosion processes. Of course, this was dependent on the quantity of hydrogen produced and therefore on the exposure conditions.

Indeed, the conditions of exposure to an aggressive medium are another major factor affecting the corrosion susceptibility of metallic alloys [19-24]; cyclic corrosion tests with wet and dry phases modified the corrosion susceptibility of aluminum alloys compared with continuous immersion tests [24]. Larignon et al. showed that, after cyclic corrosion tests, a high hydrogen amount was detected inside a corroded 2024 aluminum alloy [24]. The influence of the exposure conditions to the aggressive medium is particularly true for aircraft structures because they are cyclically exposed to corrosive environments throughout their life. Indeed, when the plane is on the tarmac, the plane is exposed to a corrosive environment and sometimes to high temperatures; however, during a flight, the exposure duration to the corrosive environment decreases. Additionally, for some parts of the structure, the temperature falls to roughly $-50^{\circ} \mathrm{C}$, whereas other parts of the structure are maintained at room temperature.

The aim of this work is to study the effect of varying conditions of exposure to an aggressive medium on the corrosion susceptibility of the 2050 alloy. To apply testing conditions similar to real exposure conditions, corrosion tests with alternate immersion and emersion phases were performed in the laboratory. Because the corrosion susceptibility of the alloy strongly depends on its precipitation state, the 2050 alloy was studied in both its asreceived state, which is associated with a low volume fraction of precipitates, and in an aged state, which is characterized by a large precipitation of $T_{1}$ phases. Comparison of the results obtained for the two metallurgical states will help in understanding the influence of $T_{1}$ precipitates on the corrosion morphology depending on the exposure conditions to the aggressive medium and will be helpful to obtain data about hydrogen trapping at $\mathrm{T}_{1}$ precipitates. Therefore, these two metallurgical states were exposed to continuous immersion and to cyclic corrosion tests to study the effect of environmental exposure conditions on their corrosion behavior.

\section{Experimental}

\subsection{Material}

The material for this study was an aluminum-copper-lithium AW (Airware) 2050 alloy (Al base, 3.86\% Cu, 0.86\% Li; wt\%) provided by Constellium (France). The material was received as a $50 \mathrm{~mm}$ thick plate obtained by hot rolling, followed by solutioning, water quenching, stretching and natural ageing at room temperature, leading to the T34 metallurgical state. In this metallurgical state, according to the literature [25], hardening $T_{1}$ precipitates were not present in the grains. Therefore, to promote the formation of hardening $T_{1}$ precipitates in the grains, a piece of the plate received a heat treatment corresponding to an artificial ageing treatment at $155^{\circ} \mathrm{C}$ for $30 \mathrm{~h}$. In the following text, samples in the T34 metallurgical state and aged samples are called NHT (non-heat treated) and HT (heat-treated), respectively. The two metallurgical states are of interest from an industrial point of view. Friction stir welding (FSW) joints of Al-Cu-Li alloys constitute promising solutions to replace the riveted structures of aluminum alloys. The welded joints could be obtained by welding two plates in the T34 metallurgical states; after the welding process, the joints are submitted to an artificial ageing, without solutioning before the ageing, to increase their mechanical properties [7]. Therefore, the HT alloy corresponds to the metallurgical state of the base metal after the post-welding heat-treatment. Due to the rolling process, the microstructure of the material presented grains strongly elongated in the rolling (longitudinal) direction. The average grain sizes in the longitudinal (L), transversal (LT) and short transversal (ST) directions were 500,350 and $60 \mu \mathrm{m}$, respectively. Electron backscattered diffraction (EBSD) observations (Fig. 1a; see the experimental section below for EBSD explanations) showed the strong morphological anisotropy of the material. Scanning Electron Microscope (SEM), using a JEOL 7000F field emission gun SEM, allowed coarse $\mathrm{Al}-\mathrm{Cu}-\mathrm{Mn}-\mathrm{Fe}$ particles to be observed both for NHT and HT samples. Their density and distribution (both in the grains and at the grain boundaries) were similar for the two metallurgical states because the artificial ageing at $155^{\circ} \mathrm{C}$ could not change the distribution of coarse particles. These particles were not studied with more details because they mainly influence the susceptibility to pitting corrosion of the alloy. The finer precipitation, i.e. the distribution of $T_{1}$ precipitates, was described in the experimental results and discussion part.

\subsection{Corrosion tests}

All corrosion tests were performed in a $0.7 \mathrm{M} \mathrm{NaCl}$ solution maintained at a temperature of $25^{\circ} \mathrm{C}$ using a Julabo refrigerated circulator in a laboratory room at a controlled temperature $\left(25^{\circ} \mathrm{C} \pm 1^{\circ} \mathrm{C}\right)$. This chloride concentration is representative of the chloride content for the solutions used during Mastmaasis Wet Bottom test, an industrial corrosion test used by Constellium. For the most part, corrosion tests corresponded to four exposure conditions with two cyclic corrosion tests and two continuous immersion tests (Table 1). For all the tests, during the immersion periods, the samples were hanged in the corrosion cell by using a thin nylon yarn. Cyclic corrosion tests (CR $72 \mathrm{~h}$ and CF $72 \mathrm{~h}$ ) consisted of three $24 \mathrm{~h}$ cycles; each cycle was composed of a $3 \mathrm{~h}$ immersion in the electrolyte, which was followed by a $5 \mathrm{~h}$ dry period in air, then a $2 \mathrm{~h}$ immersion period and, finally, a $14 \mathrm{~h}$ dry period in air. During the air exposure periods (emersion phase), the samples were hanged by using the nylon yarn in a sample glass store placed in the laboratory room $\left(25^{\circ} \mathrm{C} \pm 1{ }^{\circ} \mathrm{C}\right)$ for the $\mathrm{CR} 72 \mathrm{~h}$ tests and, for the $\mathrm{CF} 72 \mathrm{~h}$ tests, the samples were hanged in a container maintained at a negative temperature equal to $-25^{\circ} \mathrm{C} \pm 1^{\circ} \mathrm{C}$. For comparison, two continuous immersion tests (CI $15 \mathrm{~h}$ and $\mathrm{CI} 72 \mathrm{~h}$ ) were also performed with durations of $15 \mathrm{~h}$ and $72 \mathrm{~h}$. The $\mathrm{pH}$ was monitored during the continuous immersion tests. It was equal to 5.7 at the beginning of the test and became equal to 7.65 after $72 \mathrm{~h}$ for both NHT and HT samples. The duration of the first continuous immersion test represented the cumulated immersion time for cyclic corrosion tests, and the duration of the second one represented the total duration for the cyclic tests. For a few tests, to amplify the corrosion damage, cyclic tests consisted of seven $24 \mathrm{~h}$ cycles; these tests were called CR $168 \mathrm{~h}$ and CF $168 \mathrm{~h}$ (Table 1). For these tests, a $168 \mathrm{~h}$ continuous immersion test (CI $168 \mathrm{~h}$ ) was considered as a reference. All corrosion tests were performed on cubic samples ( $10 \mathrm{~mm}$ edge) extracted from the core of the plate. The plane exposed to the aggressive medium was the LTST plane to observe the propagation of the corrosion defects in the rolling direction, which is the most critical direction for corrosion propagation because of the morphological texture of the material. Before corrosion tests, the samples were mechanically abraded up to 4000 grade, then polished with $3 \mu \mathrm{m}$ and $1 \mu \mathrm{m}$ diamond paste, rinsed in distilled water and air-dried. After corrosion tests, the samples were cut along the L-ST plane to obtain cross-sections for the analysis of the propagation of the corrosion in the bulk of the samples (Fig. 1b). Cross-sections were polished and then observed using optical $(\mathrm{OM})$ and scanning electron microscopes (SEM; see experimental part below). To quantify the corrosion damage, a statistical analysis was performed from many polished cross-sections. Considering the cumulative length of the corroded surface observed in the ST direction, which was estimated at 


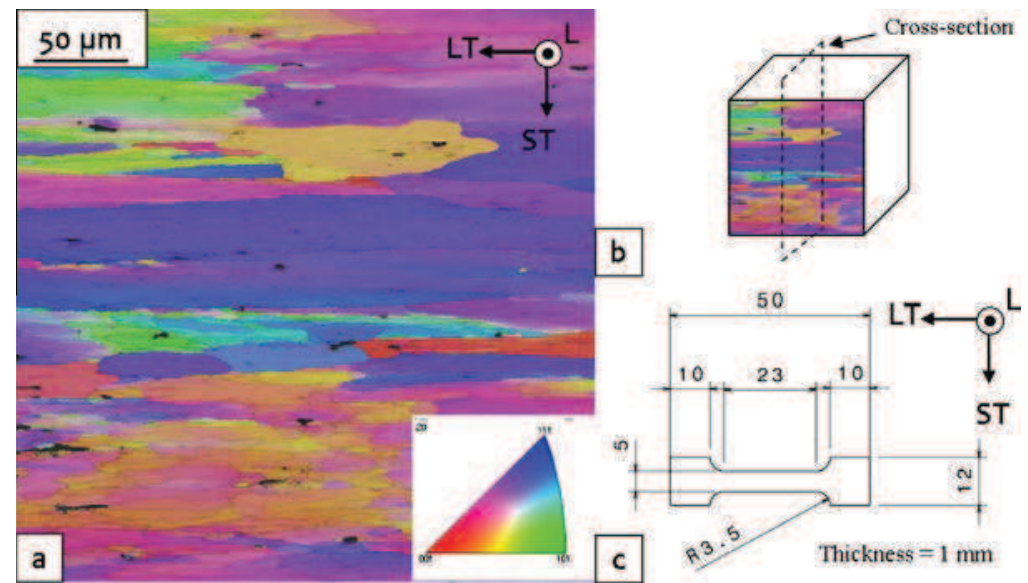

Fig. 1. (a) EBSD/IPF-z0 map of the LT-ST plane of the 2050 NHT alloy; (b) schema of a cubic sample used for corrosion tests; (c) schema of a tensile specimen (size in mm).

Table 1

Description of the corrosion tests.

\begin{tabular}{|c|c|c|c|c|}
\hline Exposure conditions & \multicolumn{4}{|c|}{ Continuous immersion (samples left at OCP) } \\
\hline \multirow[t]{2}{*}{ Description of the tests/Name of the tests } & \multicolumn{4}{|c|}{ Continuous immersion in $0.7 \mathrm{M} \mathrm{NaCl}$ at room temperature $\left(25 \pm 1^{\circ} \mathrm{C}\right)$} \\
\hline & \multicolumn{3}{|c|}{ Duration $=15 \mathrm{~h} \mathrm{CI} 15 \mathrm{~h} \quad$ Duration $=72 \mathrm{~h} \mathrm{CI} 72 \mathrm{~h}$} & Duration $=168 \mathrm{~h} \mathrm{CI} 168 \mathrm{~h}$ \\
\hline Exposure conditions & \multicolumn{4}{|c|}{$\begin{array}{l}\text { Cyclic corrosion test }=\text { alternate immersion }\left(0.7 \mathrm{M} \mathrm{NaCl} \text { at } 25 \pm 1{ }^{\circ} \mathrm{C} \text {; samples left at } \mathrm{OCP}\right) \text { and emersion } \\
\text { periods }\end{array}$} \\
\hline \multirow[t]{8}{*}{ Description of the tests/Name of the tests } & \multirow{4}{*}{\multicolumn{4}{|c|}{$\begin{array}{l}n 24 \mathrm{~h} \text { cycles }(n=\text { number of cycles }) \\
\text { A cycle }=3 \mathrm{~h} \text { immersion } / 5 \mathrm{~h} \text { dry period } / 2 \mathrm{~h} \text { immersion } / 14 \mathrm{~h} \text { dry period } \\
\text { Cumulated immersion time }=n \times(3+2)=5 n \\
\text { Duration of the cyclic corrosion test }=n \times(3+5+2+14)=24 n\end{array}$}} \\
\hline & & & & \\
\hline & & & & \\
\hline & & & & \\
\hline & \multirow{2}{*}{\multicolumn{2}{|c|}{$\begin{array}{l}\text { Temperature during the dry } \\
\text { period }=25 \pm 1^{\circ} \mathrm{C} \\
\text { CR tests }\end{array}$}} & \multirow{2}{*}{\multicolumn{2}{|c|}{$\begin{array}{l}\text { Temperature during the dry } \\
\text { period }=-25 \pm 1^{\circ} \mathrm{C} \\
\mathrm{CF} \text { tests }\end{array}$}} \\
\hline & & & & \\
\hline & $\begin{array}{l}n=3 \text { cycles } \\
(3 * 24=72)\end{array}$ & $\begin{array}{l}n=7 \text { cycles } \\
(7 * 24=168)\end{array}$ & $\begin{array}{l}n=3 \text { cycles } \\
(3 * 24=72)\end{array}$ & $\begin{array}{l}n=7 \text { cycles } \\
(7 * 24=168)\end{array}$ \\
\hline & CR $72 \mathrm{~h}$ & CR $168 \mathrm{~h}$ & $\mathrm{CF} 72 \mathrm{~h}$ & CF $168 \mathrm{~h}$ \\
\hline
\end{tabular}

$80 \mathrm{~mm}$, and the average grain size in this direction, which was estimated at $60 \mu \mathrm{m}$, more than 1000 grains and grain boundaries were analyzed for one sample. Three parameters were considered to statistically describe the morphology of the corrosion defects: the average propagation depth of the corrosion defects in the L direction, the average propagation in the ST direction and the linear density of corrosion defects measured in the ST direction (number of defects per unit length).

During some corrosion tests, open circuit potential (OCP) and electrochemical impedance spectroscopy (EIS) measurements were performed using a Biologic potentiostat. A three electrode electrochemical cell was used, which included a platinum electrode as the auxiliary electrode and a saturated calomel electrode (SCE) as the reference electrode. Potentials quoted in the manuscript refer to the SCE. Specimens used as the working electrode were $1 \mathrm{~cm}^{2}$ surface samples coated in an epoxy resin. The plane exposed to the electrolyte was the LT-ST plane. Impedance measurements were performed using as disturbance a sinusoidal potential of an amplitude, which was limited to $10 \mathrm{mV}$ (rms). The frequency range varied between $3 \mathrm{kHz}$ and $10 \mathrm{mHz}$. The acquisition parameters were adapted according to the frequency range used. For all the corrosion tests, the samples were left at their OCP and several impedance measurements were carried out during the corrosion tests to characterize the corrosion behavior of the samples as a function of time. Between each impedance measurement, the samples were left at their corrosion potential and, before all impedance measurements, the OCP was measured for $5 \mathrm{~min}$ to take into account the evolution of the OCP as a function of time.
This potential value was potentiostatically maintained during the impedance measurements. For continuous immersion tests, the first impedance measurement was performed $20 \mathrm{~min}$ after the beginning of the corrosion test, following a 5 min step of OCP measurement while the second impedance measurement was performed after $12 \mathrm{~h}$. Therefore, except for the first measurement, the samples were in a steady state during the impedance measurements (see the experimental result part for OCP evolution). For cyclic corrosion tests, impedance diagrams were plotted at the beginning and at the end of each immersion period from the second immersion period ( $8 \mathrm{~h}$ after the beginning of the cyclic corrosion tests). With the $5 \mathrm{~min}$ of OCP measurements before each impedance measurements, by taking into account the low value of the disturbance amplitude and the frequency range that was shortened, the samples were considered in a steady state during the impedance measurements. All measurements were repeated three times to ensure their reproducibility.

\subsection{Characterization of the microstructure and of the corrosion morphology}

EBSD scans were performed using a JEOL 7000F field emission gun SEM at an accelerating voltage of $15 \mathrm{kV}$ with a Nordlys II F+ camera. EBSD measurements were helpful in both analyzing the microstructure of the alloy (Fig. 1a) and characterizing the corrosion morphology. Thus, EBSD maps were performed on $2 \mathrm{~mm}^{2}$ areas with a step size of $1 \mu \mathrm{m}$ before and after corrosion tests. Maps that are more precise were also performed around corrosion 
defects with a step size of $0.5 \mu \mathrm{m}$. The orientation data were postprocessed with the commercial orientation imaging software package Oxford Channel 5. The inverse pole figure (IPF) maps represent the crystal orientation parallel to the normal sample surface. Moreover, a Nikon ECLIPSE MA200 OM and a SEM (ZEISS EVO HD LS15; incident electron beam kept at $15 \mathrm{kV}$ ) were used to carefully examine the microstructure of the material and the corrosion defects. Transmission electron microscopy (TEM) using a JEOL-JEM-2010 microscope also allowed various types of precipitates to be observed. Specifically, $300-\mu \mathrm{m}$ slices were removed from the samples and were ground to a thickness of $100 \mu \mathrm{m}$. A dimple was machined in the central region using a South Bay Technology dimpler with a methanol $(900 \mathrm{~mL}) /$ nitric acid $(300 \mathrm{~mL})$ mixture.

\subsection{Mechanical tests and hydrogen measurements}

Mechanical tests were performed to evaluate the residual mechanical properties of the corroded samples. Tensile tests were performed on tensile specimens (Fig. 1c) at a strain rate of $10^{-3} \mathrm{~s}^{-1}$ using an Instron testing machine equipped with a $10 \mathrm{kN}$ load cell. Mechanical tests were performed on unexposed samples and on pre-corroded samples prepared according to the corrosion testing conditions previously described. The LT-ST planes of the tensile specimens were exposed to the medium, with the other planes protected by a varnish, and the samples were strained along the LT direction. To amplify the corrosion effects on the mechanical behavior, pre-corrosion tests corresponded to CR $168 \mathrm{~h}$ and CF $168 \mathrm{~h}$ (7 cycles). Therefore, CI $168 \mathrm{~h}$ tests were compared with the cyclic tests CR $168 \mathrm{~h}$ and $\mathrm{CF} 168 \mathrm{~h}$ in terms of the residual mechanical properties of the tensile specimens (Table 1 ). Hydrogen content measurements were performed using a Horiba EMGA621W and a Brüker Galileo HMat Instrumental Gas Analyzers (IGA) in which the sample was heated until $1200^{\circ} \mathrm{C}$. Before performing measurements, the corrosion products were removed from the surface by mechanical polishing, and the samples were cut into small pieces of approximately $0.1 \mathrm{~g}$. Both tensile tests and hydrogen content measurements were repeated three times for each condition.

\section{Experimental results and discussion}

\subsection{Corrosion susceptibility of the 2050 alloy during continuous immersion tests}

To study the effect of environmental exposure conditions on the corrosion susceptibility of the 2050 alloy, first, continuous immersion tests were performed in chloride solution for both NHT and HT alloys. Fig. 2a and b show optical micrographs of corrosion defects for a NHT sample after $15 \mathrm{~h}$ and $72 \mathrm{~h}$ of continuous immersion. The NHT alloy was found to be susceptible to intergranular corrosion. By comparing the EBSD analysis (Fig. 2c) and SEM observations (Fig. 2d) of the same corrosion defects, the dissolution of grain boundaries was evidenced. This result seems to be consistent with another study [25] in which the authors explained the susceptibility of the 2050 alloy to intergranular corrosion by the presence of $\mathrm{T}_{1}$ phases at grain boundaries. Because of the more negative potential of $\mathrm{T}_{1}$ precipitates compared with that of the matrix, a galvanic coupling occurs at the expense of $\mathrm{T}_{1}$, which leads to grain boundary dissolution [25]. Furthermore, Li et al. show that the potential of $\mathrm{T}_{1}$ precipitates was shifted to a more positive value for a long immersion time due to the preferential dissolution of $\mathrm{Li}$ from $\mathrm{T}_{1}$ and to the resulting copper enrichment of the particles [15]. Consequently, the intergranular corrosion associated with the presence of $\mathrm{T}_{1}$ phases at grain boundaries might be due to the alternate anodic dissolution of the $T_{1}$ precipitates and to that of the surrounding matrix. However, in the present work, unlike observations in the literature, no $\mathrm{T}_{1}$ precipitation was observed at grain boundaries for the NHT alloy (Fig. 2e). TEM observation along [011] zone axis clearly showed the absence of $\mathrm{T}_{1}$ precipitate on the micrograph and the absence of characteristic strikes on the selected area diffraction pattern. It was assumed that intergranular susceptibility should be caused by a preferential segregation of alloying elements, i.e., most likely $\mathrm{Cu}$ and/or Li, at grain boundaries. Further analyses are in progress to assess the relevancy of this hypothesis. However, notably, this work shows that the presence of $\mathrm{T}_{1}$ precipitates at grain boundaries is not required to obtain intergranular corrosion for the 2050 alloy. A comparison of Fig. 2a and b shows a widening of corrosion defects when the corrosion time increases. During the first hours of immersion, the corrosion defects corresponded to thin grooves limited to grain boundary areas, whereas, after a longer immersion time, corrosion grooves are quite wide and extend in the grain. Furthermore, the observations (Fig. 2a-d) show that the propagation paths are nearly linear and that most of the defects corresponded to the dissolution of one or two connected grain boundaries.

To better describe the corrosion damage, a statistical analysis was performed. Fig. 3 shows the average propagation depth of the corrosion defects in the $\mathrm{L}$ direction and their average propagation width in the ST direction for both NHT and HT samples after different corrosion tests. It can be added that, when several corroded grain boundaries were connected, these boundaries were considered only one corrosion defect. Therefore, when the alloy is susceptible to intergranular corrosion, the last criterion, i.e., the propagation width in the ST direction, allows the evaluation of the branching of the corrosion defects, assuming that, for a corroded grain boundary considered individually, its average width in the ST direction was less than $1 \mu \mathrm{m}$ and approximately $2-3 \mu \mathrm{m}$ after $\mathrm{CI} 15 \mathrm{~h}$ and $\mathrm{CI} 72 \mathrm{~h}$, respectively. The 3rd parameter is the number of corrosion defects observed per mm of cross sections analyzed and is called the "linear density of corrosion defects". For NHT samples, after continuous immersion tests, the quantification of the corrosion susceptibility, according to the corrosion exposure time, shows an increase in the defects size when the corrosion exposure time increases. Considering the propagation along the L direction, after a $\mathrm{CI} 72 \mathrm{~h}$ corrosion test, corrosion defects are longer than for a CI $15 \mathrm{~h}$ corrosion test, with propagation depths equal to 100 and $160 \mu \mathrm{m}$, respectively. Surprisingly, the linear density of corrosion defects was smaller after $\mathrm{CI} 72 \mathrm{~h}$ compared with $\mathrm{CI} 15 \mathrm{~h}$ tests. This result could be explained by the stronger density of pits in the $\mathrm{CI}$ $72 \mathrm{~h}$ samples compared with CI $15 \mathrm{~h}$ samples. For the CI $15 \mathrm{~h}$ samples, no pit was observed in the L-ST plane for a cumulative length observed in the ST direction of $80 \mathrm{~mm}$. On the contrary, for the $\mathrm{CI}$ $72 \mathrm{~h}$ samples, 19 pits were observed in the L-ST plane for a cumulative length observed in the ST direction of $40 \mathrm{~mm}$. Their mean depth in the $\mathrm{L}$ direction was $17 \mu \mathrm{m}$ with values between 11 and $25 \mu \mathrm{m}$. Many intergranular corrosion defects were assumed to initiate after $\mathrm{Cl} 72 \mathrm{~h}$ tests; however, these defects did not propagate enough to be detected due to pit propagation in their surroundings. This hypothesis suggested that the interactions between the two types of corrosion, i.e., pitting and intergranular corrosion, significantly affected intergranular corrosion propagation.

For the HT alloy, the material was susceptible to intragranular corrosion (Fig. 4a and b). The EBSD analysis (Fig. 4c), which was combined with SEM observations (Fig. 4d) of the same corrosion defect confirmed this corrosion morphology. TEM observations along [011] zone axis (Fig. 4e) showed the presence of $\mathrm{T}_{1}$ precipitates both in the grains and at the grain boundaries with characteristic strikes of needles observed on the selected area diffraction pattern. The susceptibility of the HT alloy to intragranular corrosion was due to the precipitation of $\mathrm{T}_{1}$ phases both in the grain and at the grain boundaries, which is in agreement with the 


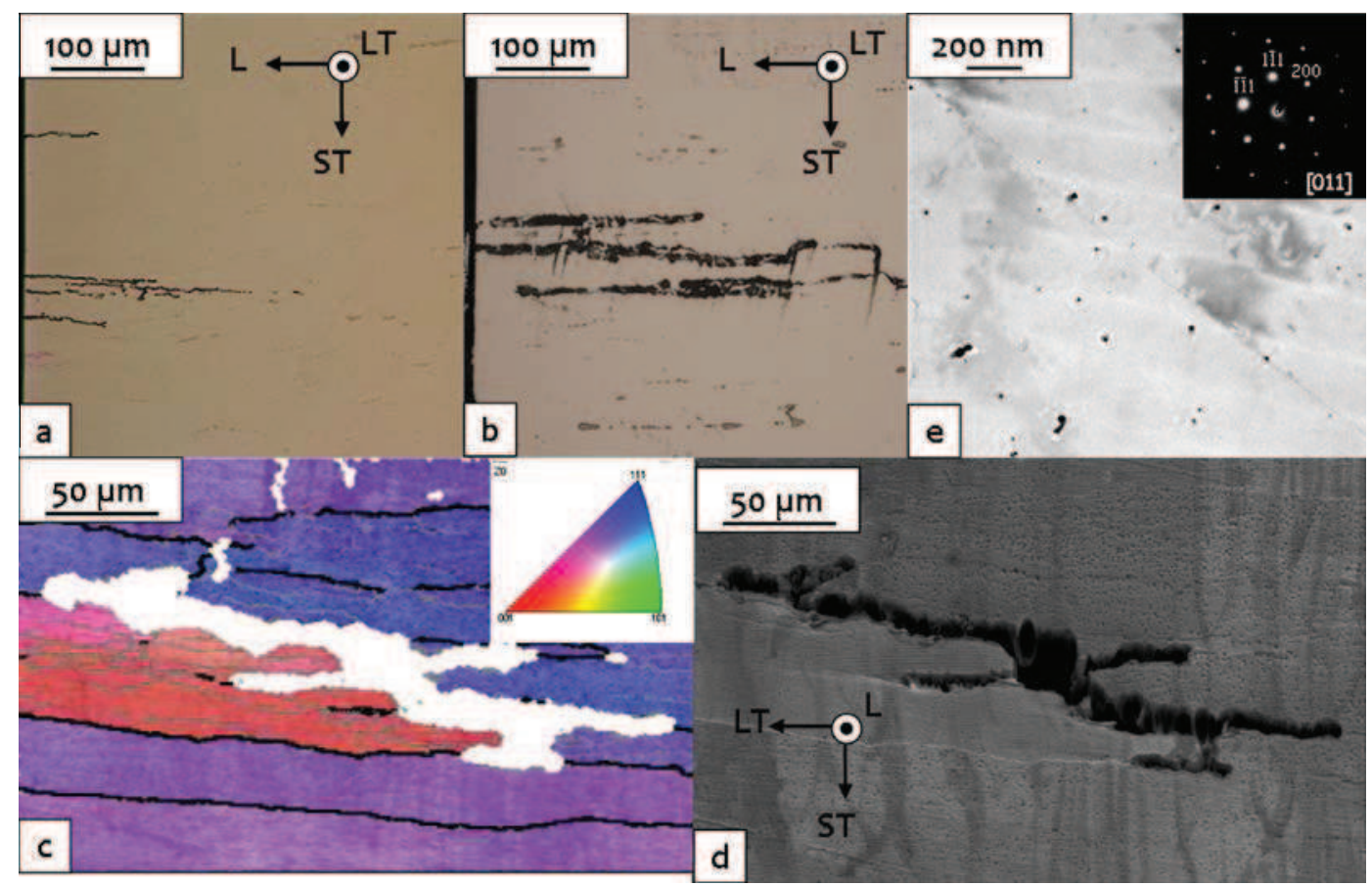

Fig. 2. NHT sample. OM observations of intergranular corrosion defects after (a) CI $15 \mathrm{~h}$ and after (b) CI $72 \mathrm{~h}$; (c) EBSD observations of a corrosion defect after a continuous immersion test; (d) SEM observations of the corrosion defect shown in (c); (e) TEM observation along [011] zone axis: no $\mathrm{T}_{1}$ precipitate visible on the micrograph and absence of characteristic strikes on the selected area diffraction pattern.

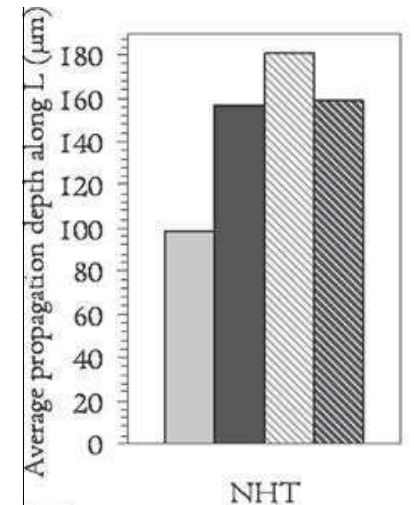

a

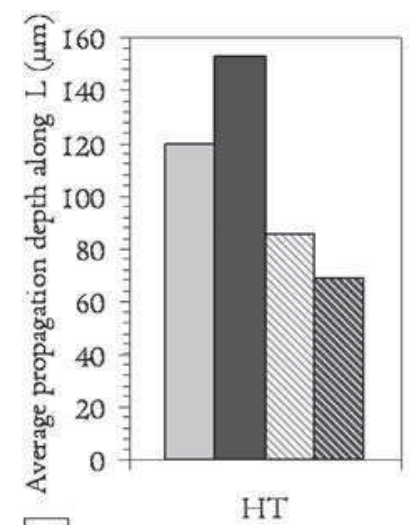

d
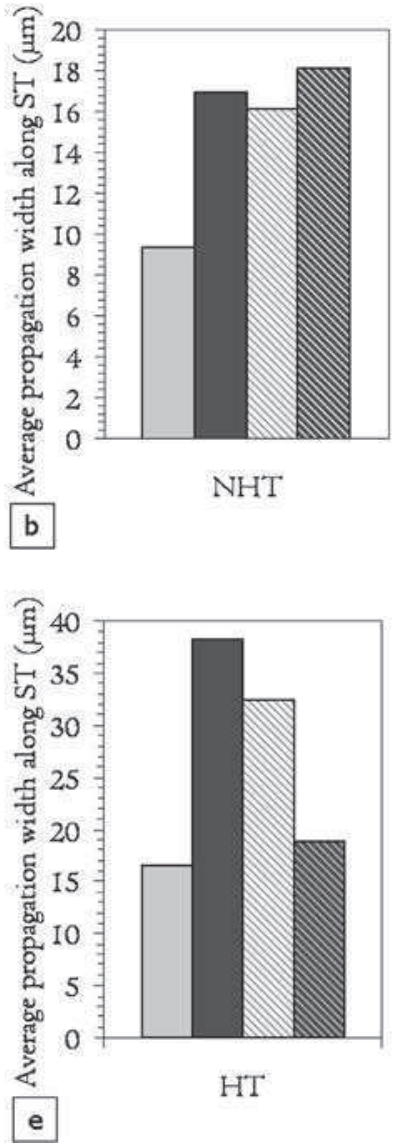
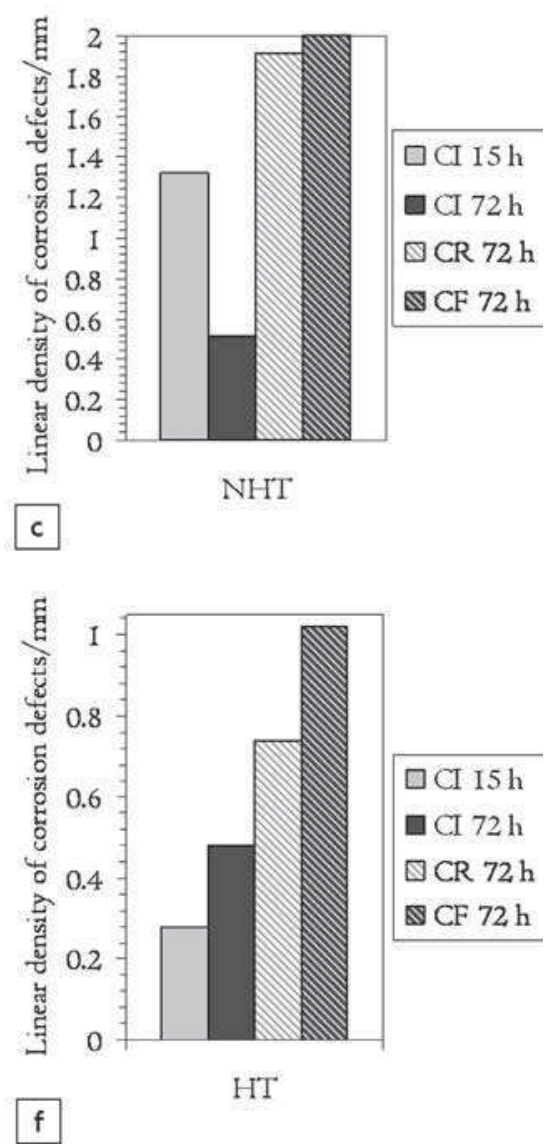

Fig. 3. Average propagation depth of corrosion defects for NHT samples in (a) L and (b) ST directions and for HT samples in (d) L and (e) ST directions. Linear density of corrosion defects in the ST direction for (c) NHT and (f) HT samples. The data are given for both continuous immersion tests and cyclic corrosion tests. 


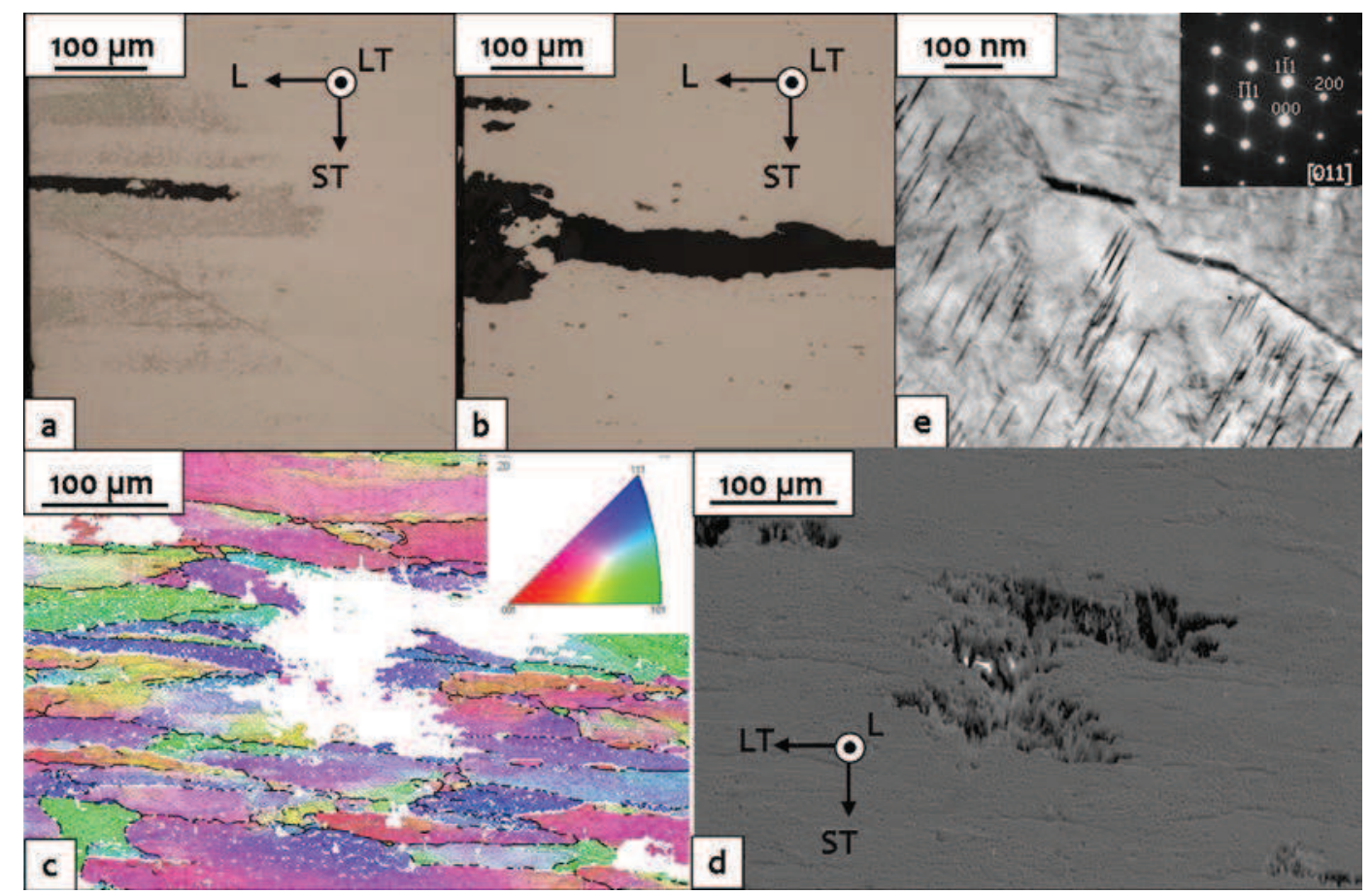

Fig. 4. HT sample. OM observations of intragranular corrosion defects after (a) CI $15 \mathrm{~h}$ and after (b) CI $72 \mathrm{~h}$; (c) EBSD observations of a corrosion defect after a continuous immersion test; (d) SEM observations of the corrosion defect shown in (c); (e) TEM observation of hardening $\mathrm{T}_{1}$ precipitates along [011] zone axis: micrograph and selected area diffraction pattern with characteristic strikes of needles.

literature [25]. Indeed, as previously explained, microgalvanic coupling phenomena between $\mathrm{T}_{1}$ phases and the matrix must be considered. When the NHT samples were aged to obtain HT samples, $\mathrm{T}_{1}$ precipitates formed in the grain boundaries; however, numerous $\mathrm{T}_{1}$ precipitates also formed inside the grains. Therefore, both the corrosion potentials of the grain boundaries and the grains became more negative with a decrease in the difference between the two corrosion potential values. The galvanic coupling effect between the grains and the grain boundaries was reduced so that intergranular corrosion did not occur. Moreover, with a more negative potential due to the presence of $\mathrm{T}_{1}$ precipitates and to a lower copper content, the grains in the HT samples were more reactive, which led to intragranular corrosion. Concerning the influence of the immersion time in the chloride solution, corrosion defects were both longer (L direction) and wider (ST direction), and their linear density increased (Figs. 3d-f), when the immersion time increased.

Importantly, the EBSD analysis showed strong heterogeneities in the material studied, with a wide range of grain sizes and with the presence of subgrain boundaries. It is well known that the propagation of corrosion defects is strongly dependent on the morphology of the grains. Thus, there will most likely be a great discrepancy in the corrosion morphology from one corrosion defect to another, depending on the local microstructure, and the results displayed in this study can vary according to the sample. Moreover, the measurements of corrosion depth are always subjective and depend strongly on the quality of the surface preparation before the OM observations. A previous study performed on a 2024 alloy showed that it was difficult to obtain relevant data concerning the corrosion depth by analyzing corroded surfaces [26]. Therefore, it was assumed that the errors concerning the previous corrosion depths could be significant. This situation is particularly true when the number of corrosion defects is low, which is the case for the continuous immersion tests. In this case, the electrolyte is not renewed during the entire test, and the stirring is most likely not enough to remove corrosion products during the test, which limits the initiation of corrosion defects.

Then, to help in analyzing the morphology of the corrosion defects, tensile tests were performed because these tests allow the analysis of a large volume of the alloy and, therefore, to obtain a more global response from the material. Furthermore, Augustin et al. showed that if the shape of the tensile curve for a pre-corroded sample remains unchanged compared with a reference curve for a non-corroded specimen, with a homothetic shift in the flow stress, then one can assume that the corrosion damage is homogeneously distributed along the gauge length and that the corroded zone can be considered a non-load bearing zone [26]. Fig. 5a shows the tensile curves obtained for non-corroded and CI $168 \mathrm{~h}$ NHT samples. No homothetic shift in the flow stress was observed from a non-corroded sample to a corroded sample. This result demonstrated that the morphology of the corrosion defects, i.e., thin intergranular corrosion defects with a rather low linear density, did not allow the generation of a non-load bearing zone, considering the direction of the stress during the tensile tests. For HT samples, the results were different, with a slight shift in the flow stress for $\mathrm{CI} 168 \mathrm{~h}$ samples compared with non-corroded samples (Fig. 6a); for a true strain equal to $5 \%$, the stress was decreased from $590 \mathrm{MPa}$ to $575 \mathrm{MPa}$ for a non-corroded to a CI $168 \mathrm{~h}$ samples respectively. This corresponded to a $3.5 \%$ shift of the flow stress. This result could be attributed to the corrosion defect morphology observed for HT samples, i.e., intragranular corrosion defects, and showed that the tensile tests slightly emphasized the difference in the corrosion behavior for NHT and HT samples. Notably, for both NHT and HT samples, a significant decrease in the elongation to failure was observed for corroded samples compared with noncorroded samples.

Additional electrochemical measurements were performed for both NHT and HT samples during continuous immersion in the chloride solution to better analyze their corrosion behavior. Fig. 7a shows a decrease in the OCP for NHT samples when the 

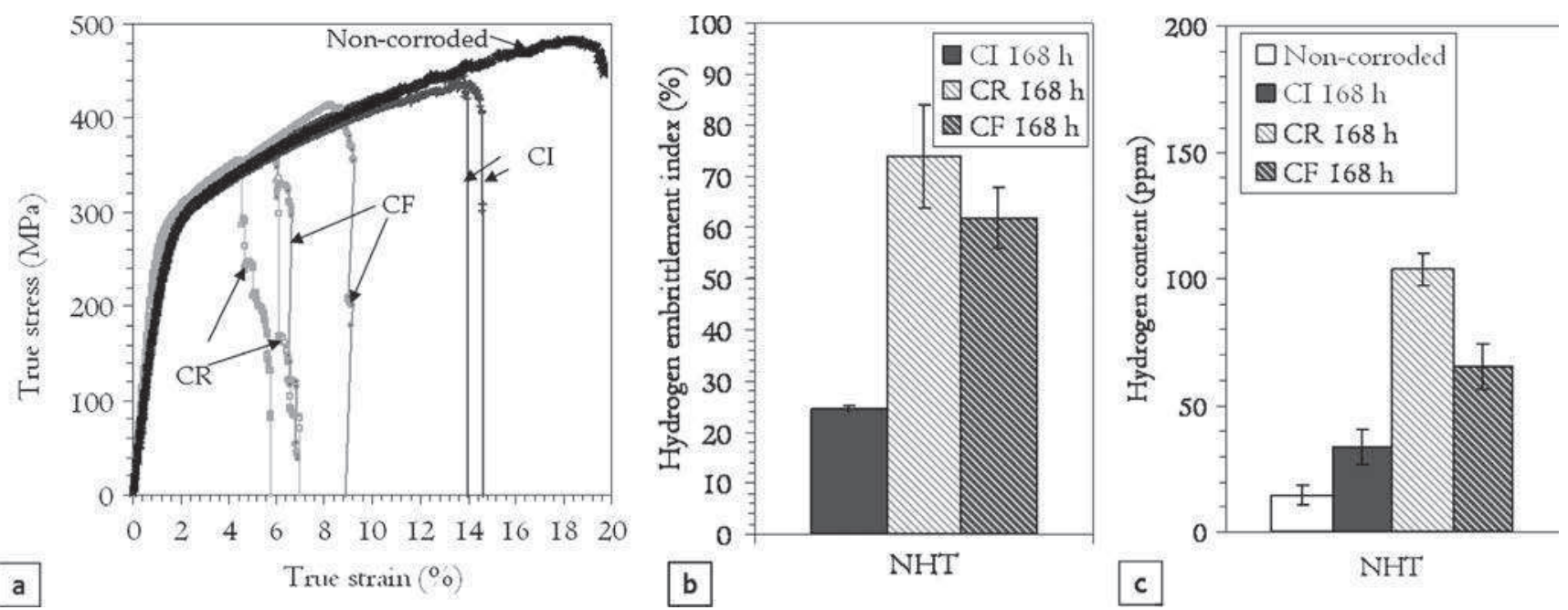

Fig. 5. (a) Tensile curves obtained for the NHT samples of a 2050 aluminum alloy. The curves are plotted for non-corroded samples and for samples pre-corroded during CI 168 h, CR 168 h and CF 168 h tests; (b) Hydrogen embrittlement index; (c) Hydrogen content measurements for corroded samples according to exposure conditions.
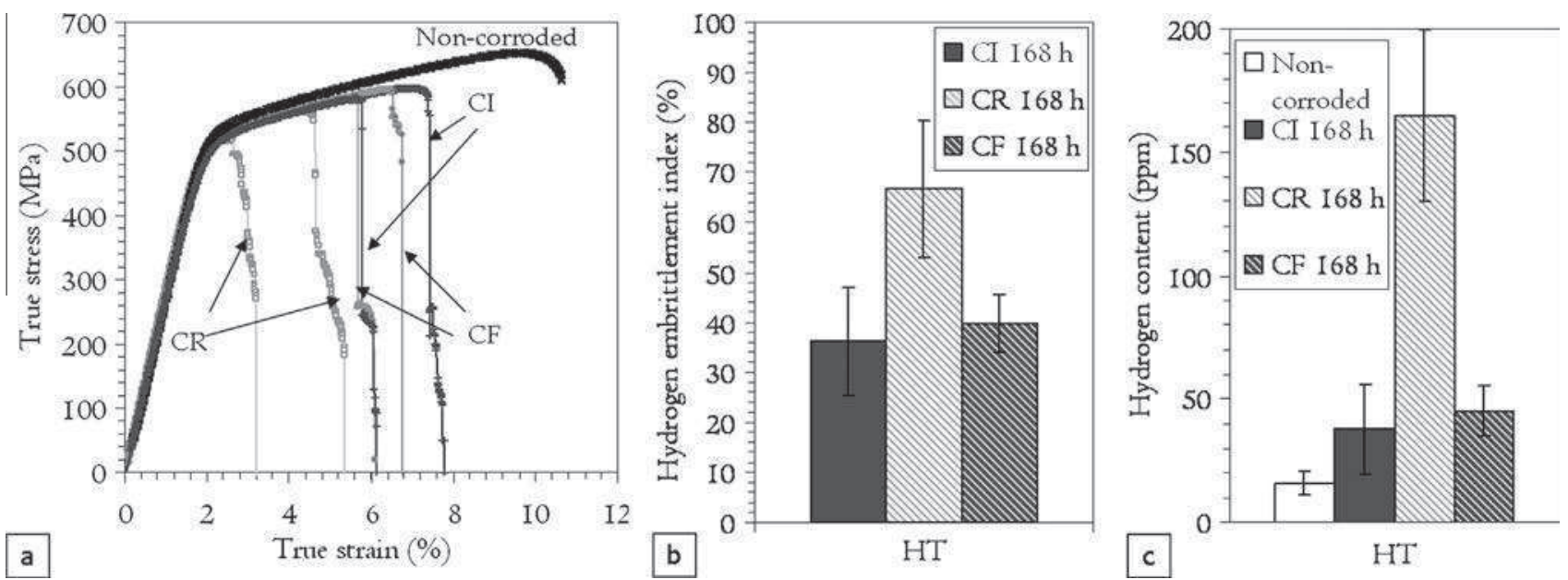

Fig. 6. (a) Tensile curves obtained for the HT samples of a 2050 aluminum alloy. The curves are plotted for non-corroded samples and for samples pre-corroded during CI 168 h, CR 168 h and CF 168 h tests; (b) Hydrogen embrittlement index; (c) Hydrogen content measurements for corroded samples according to exposure conditions.
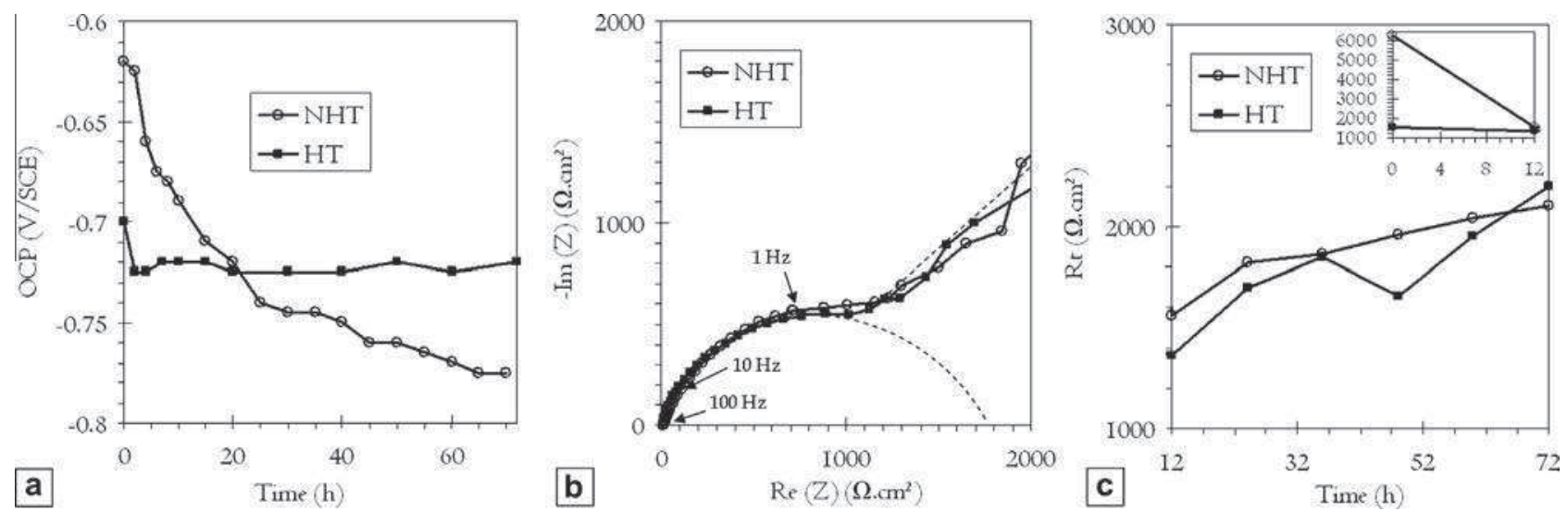

Fig. 7. Evolution of the electrochemical parameters during continuous immersion in $0.7 \mathrm{M} \mathrm{NaCl}$. (a) Open circuit potential (OCP) as a function of immersion time for NHT and HT samples. (b) Impedance diagrams (Nyquist plots) for NHT and HT alloys after $24 \mathrm{~h}$ of continuous immersion in the electrolyte. (c) $R_{t}$ versus immersion time for NHT and HT samples.

immersion time increases from 0 to $72 \mathrm{~h}$. Two steps can be defined in the OCP variation: during the first day of immersion, an important drop in the OCP is observed, whereas during the next two days, the OCP progressively decreases and becomes nearly constant after 3 days of immersion, reaching a value of $-0.78 \mathrm{~V} / \mathrm{SCE}$. The rate of the OCP drop was calculated for four different tests; this 
rate decreased by a factor of ten between the two steps $\left(5.6 \times 10^{-3} \mathrm{mV} / \mathrm{h}\right.$ for the first $24 \mathrm{~h}$ of immersion compared with $5.6 \times 10^{-4} \mathrm{mV} / \mathrm{h}$ during the second step). The ОСР drop at the beginning of the test could be linked to the dissolution of the protective oxide [27]. Importantly, Hagyard et al. showed that the potential rose to a peak at the beginning of the immersion and that this increase was attributed to the dissolution of aluminum and to the formation of the protective oxide [28,29]. This reaction was very quick and, thus, is rarely observed, which was the case in this study because no peak was visible in Fig. 7a. After reaching the peak potential, only a small fraction of the electrode surface remains actively anodic, whereas the hydrogen release process and oxygen reduction occur over most of the metal surface. The evolution of the OCP in Fig. 7a suggests a strong dissolution of the alloy during the first step (between 0 and $24 \mathrm{~h}$ ) and then, due to the accumulation of corrosion products, the potential progressively becomes constant to reach a minimum (between 24 and $72 \mathrm{~h}$ ). Corrosion processes in the second step may be minimized compared with the first period. The effect of the immersion time could be explained by referring to the literature. By performing polarization curves in an old and in a fresh EXCO corrosion test solution for the 2024 alloy, Keddam et al. showed that both the corrosion potential and the corrosion current were lower in the old solution than in the new solution [30]. The drop in these variables was attributed to a decrease in the cathodic reaction rate. Because the cathodic reaction was the limiting step for the corrosion processes, it was assumed that for a long immersion time, corresponding to an old solution, the dissolution of the material was slowed. This assumption could be related to the size of the corrosion defects. For a short immersion time, although the anodic reaction corresponded to aluminum oxidation, the cathodic reactions most likely corresponded to oxygen reduction on the alloy surface and, when the intergranular corrosion propagated, due to the local acidification at the tip of the corrosion defect, to $\mathrm{H}^{+}$reduction inside the corrosion defect. However, oxygen reduction on the walls of the corrosion defects was also a possibility. After a long immersion time, long corrosion defects were primarily observed, with the accumulation of corrosion products inside these defects and on the surface of the sample. These defects could be rapidly considered an occluded zone characterized by a chloride-enriched electrolyte and by $\mathrm{H}^{+}$reduction as the major cathodic reaction. No oxygen reaction could occur inside the corrosion defects; this reaction was also limited on the sample surface, which led to a decrease in the electrochemical reaction rate. This hypothesis was supported by the electrochemical impedance spectroscopy measurements reported in Fig. 7b and c for both NHT and HT samples. The measurements were performed every $12 \mathrm{~h}$ during the $\mathrm{CI}$ tests. All the impedance diagrams presented a similar shape; therefore, for more clarity, only the impedance diagram plotted after $24 \mathrm{~h}$ of continuous immersion was plotted in Fig. 7b for the two alloys. Independent of the time, the impedance diagrams showed two well-defined time constants, which were most likely due to electrochemical corrosion reaction (capacitive loop) and mass transport controlled processes [31]. To describe the corrosion behavior versus time for the two alloys, the charge-transfer resistance $R_{t}$, characteristic of the corrosion processes, was extrapolated from the capacitive loop (see the dashed semi-circle plotted in Fig. 7b). Fig. 7c shows that $R_{t}$ significantly decreased during the first $12 \mathrm{~h}$ of immersion, indicating that a fast corrosion process occurred, with a fast evolution of the sample surface. $R_{t}$ then slightly increased after $24 \mathrm{~h}$ of immersion and, for longer immersion times, $R_{t}$ stabilized to a higher value. It seems relevant to relate the variation in $R_{t}$ to that of the OCP. Both the OCP and impedance measurements show a strong dissolution of the material during the first step, which is related to a defective layer due to the aggressiveness of chloride ions. In the second step, the stabilization of both the OCP and impedance values suggests minimized electrochemical processes due to the accumulation of corrosion products, which leads to the isolation of long corrosion defects from the electrolyte and to the minimization of the electrochemical processes. The accumulation of corrosion products inside the corrosion defects was perceived as the corrosion defects healing and contributed, with the oxide film formed on the sample surface, to artificially and slightly hinder the corrosion damage on the Nyquist plots. For the HT alloy, due to the presence of $\mathrm{T}_{1}$ phases in the matrix and to the lower copper content of the solid solution (due to $T_{1}$ precipitation), the initial OCP was found to be lower compared with the NHT alloy (Fig. 7a). Furthermore, for the HT samples, the OCP was quite stable versus the immersion time, in contrast to the NHT alloy. This difference in electrochemical behavior could be attributed to the greater homogeneity of the potential distribution in the HT sample due to the presence of $\mathrm{T}_{1}$ phases both in the grain and at the grain boundaries compared with NHT samples. Concerning the evolution of the impedance diagrams when the immersion time increased, for HT samples, $R_{t}$ decreased after $12 \mathrm{~h}$ of immersion, then slightly increased and finally stabilized; notably, the amplitude of the variation during the 12 first $h$ was lower compared with NHT samples, which could be related to the stability of the OCP versus the immersion time for HT samples, in contrast to NHT samples. The stabilization of the $R_{t}$ values for long immersion times was explained, as for NHT samples, by an artificial "healing" of the corrosion defects due to the accumulation of corrosion products.

3.2. Corrosion susceptibility of the 2050 alloy during cyclic corrosion tests with immersion and emersion steps at room temperature (CR tests)

Global observations of NHT corroded samples after CR tests show corrosion susceptibility similar to NHT samples after continuous immersion, with the presence of intergranular corrosion defects (Fig. 8). However, the observations highlighted significant differences in the morphology of the corrosion defects. After a CR test (Fig. 8a and b), intergranular corrosion defects are thinner and more branched than after continuous immersion (Fig. 2). The branching of the corrosion defects is clearly visible in Fig. 3b, with the high value of the average propagation depth along ST for CR samples. The fact that intergranular corrosion defects were thinner might be explained by the low duration of immersion for a CR test, which is only equal to $15 \mathrm{~h}$ for a total test duration of $72 \mathrm{~h}$. However, a comparison of the corrosion defect morphology with that of $\mathrm{CI} 15 \mathrm{~h}$ samples (Fig. 2a) shows that this explanation is not convincing or sufficient; after a cyclic corrosion test, the corrosion defects are thinner than after continuous immersion for an equivalent duration of immersion in the electrolyte. To help to explain this result, continuous immersion tests with a higher chloride concentration, i.e., $5 \mathrm{M}$, were performed (Fig. $8 \mathrm{c}$ and d); the results show that the intergranular defect morphology moves toward that observed after cyclic corrosion tests, with clearly thinner defects than those defects observed after the same immersion time in a $0.7 \mathrm{M}$ chloride solution. This result was consistent with results in the literature. For a 2024 alloy during continuous immersion tests, by testing chloride solutions with different chloride concentrations, Augustin et al. showed that the higher the chloride concentration of the electrolyte is, the thinner the intergranular corrosion defects [26]. Larignon et al. completed this study for the 2024 alloy and compared the corrosion defect morphology after continuous immersion and after cyclic corrosion tests. These authors showed the existence of a chloride concentration gradient inside the intergranular corrosion defects formed during continuous immersion and during cyclic corrosion tests. During a CR test, the chloride concentration could reach a value equal to $5 \mathrm{M}$ at the 


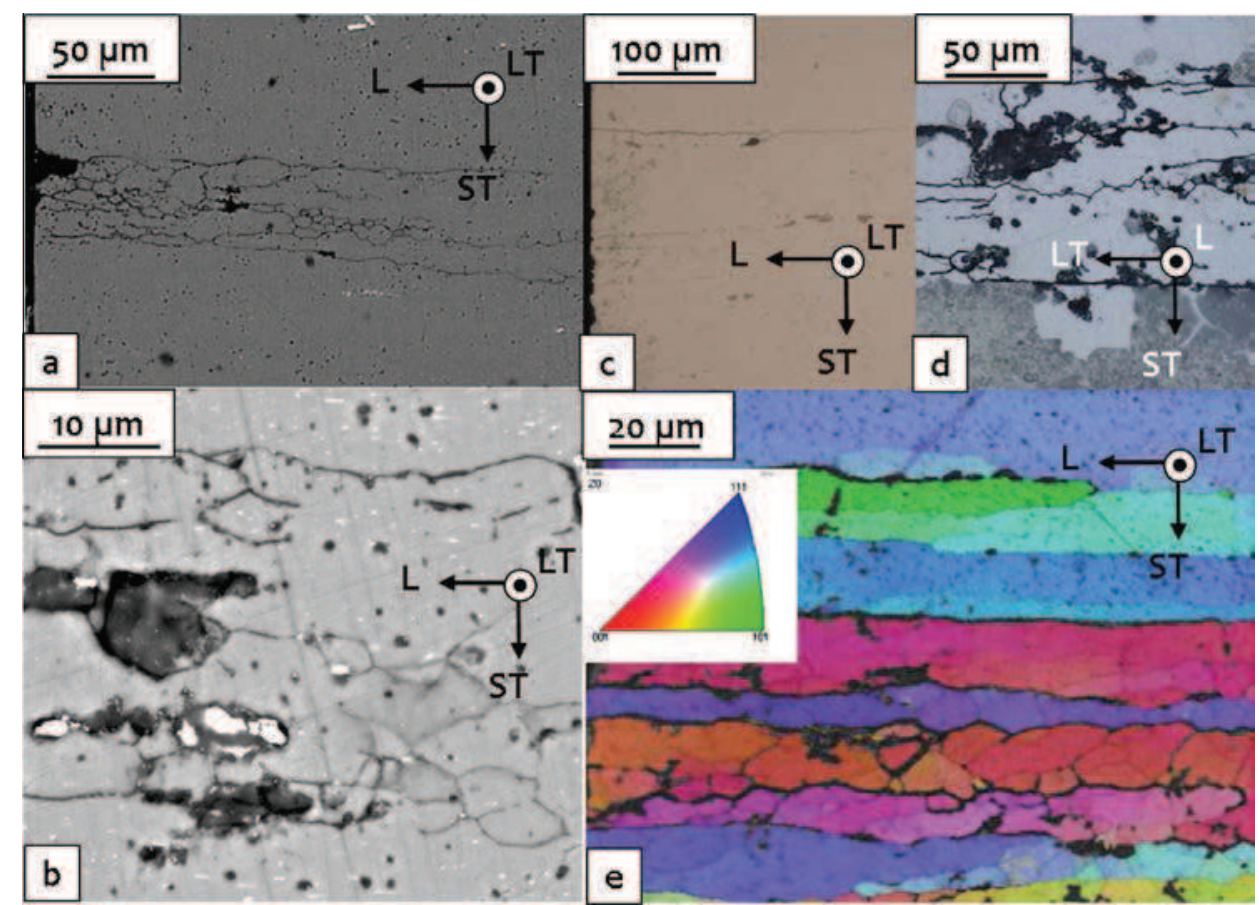

Fig. 8. (a) SEM observations of intergranular corrosion defects for NHT samples after a CR test; (b) close-up of (a). OM observations of intergranular corrosion defects for NHT samples after $\mathrm{CI} 72 \mathrm{~h}$ in $\mathrm{NaCl} 5 \mathrm{M}$ (c) in cross-section; (d) of the surface. (e) EBSD observations of intergranular corrosion defects of NHT samples after a CR test.

tip of the corrosion defect due to the evaporation of the electrolyte, which led to a partial drying of the corrosion products during the emersion period [24]. Therefore, for CR corrosion tests during the immersion period and for short defects, the cathodic reaction was primarily oxygen reduction on the sample surface, whereas the anodic reaction was the dissolution of aluminum inside the corrosion defects; the high chloride concentration inside the corrosion defects promoted their propagation based on an autocatalytic process because the more the aluminum ions were produced, the more the chloride ions penetrated into the corrosion defects, which generated a more aggressive solution. Corrosion products accumulated inside the corrosion defects so that there was rapidly little connection between the tip of the corrosion defects and the external electrolyte. Therefore, not only during the air exposure periods but also for long corrosion defects during the immersion period, the main reaction was $\mathrm{H}^{+}$reduction inside the corrosion defects, and the propagation rate of the corrosion defects primarily depended on local chemical conditions. In this case, there was no limitation by $\mathrm{H}^{+}$transport processes, which led to extensive propagation of the corrosion defects compared with continuous immersion tests. Such an explanation, which was proposed to explain the corrosion behavior of the 2024 alloy, was also convincing for the 2050 alloy and explained that the corrosion defects observed for NHT samples for CR tests were deeper (Fig. 3a) and that their linear density was higher (Fig. 3c), which could be attributed to the fact that the cathodic reduction was not a limiting reaction. To confirm this assertion, a continuous immersion test for which the solution was renewed each $24 \mathrm{~h}$ was performed on a NHT sample. The results showed that the density of corrosion defects was multiplied by five compared with a continuous immersion test in the same solution. Additionally, some grain boundaries connected to the tip of the first corroded grain boundary were also corroded, leading to a branching of the intergranular corrosion defects. Therefore, it was evidenced that a similar behavior for the 2050 alloy as for the 2024 alloy was observed during CR tests. Furthermore, a preliminary EBSD analysis performed on 2050 corroded samples showed that the corrosion also propagated at subgrain boundaries after CR tests (Fig. 8e), whereas the corrosion of subgrain boundaries was not observed after continuous immersion. This result was also comparable to observations performed for the 2024 alloy after CR tests [24]. To confirm this observation, a more accurate EBSD analysis of the corrosion defects was performed. Fig. 9 illustrates the methodology used (the example concerns a CI sample). In the first step, several zones were accurately localized. For each zone, IPF-z0 were plotted to reveal the grain and subgrains (Fig. 9c), and the misorientations were calculated to differentiate grain boundaries and subgrain boundaries. Interfaces were considered grain boundaries for misorientations higher than $10^{\circ}$ and subgrain boundaries for misorientations from $2^{\circ}$ to $10^{\circ}$. Then, the sample was slightly polished, submitted to the corrosion test, rinsed and dried. All the previously localized zones were observed using a SEM in the backscattered electron mode (Fig. 9a) to easily determine the corrosion defects due to the presence of corrosion products. Then, SEM micrographs were analyzed using an image analysis software (Image J), and the corrosion defects were highlighted (Fig. 9b) to obtain a 'corrosion map'. This map was superimposed on the IPF-z0 (Fig. 9c and d) to determine the nature of the corroded 'object' (grain or interface) and of the corroded interface (grain boundaries or subgrain boundaries). This methodology was applied for NHT samples after CI and CR tests. The results showed that the corrosion defects were localized at the grain boundaries for NHT samples after $\mathrm{CI}$ tests, which is consistent with the observations shown in Fig. 2. These results also confirmed that cyclic corrosion tests led to a modification of the corrosion morphology compared with continuous immersion tests. After CR tests, for NHT samples, corrosion extended to the subgrain boundaries (Fig. 10a-c). The explanations previously provided, i.e., the high chloride concentration reached at the tip of the corrosion defects during CR tests and the corrosion rate controlled at a local scale $\left(\mathrm{H}^{+}\right.$reduction) could explain the dissolution of subgrain boundaries.

For the HT samples after CR tests, the corrosion morphology was intragranular (Fig. 11), which is similar to that for samples 


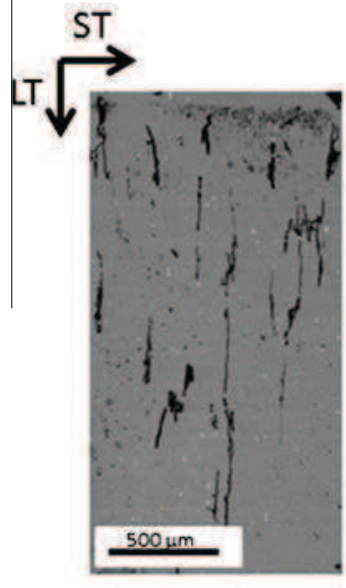

a

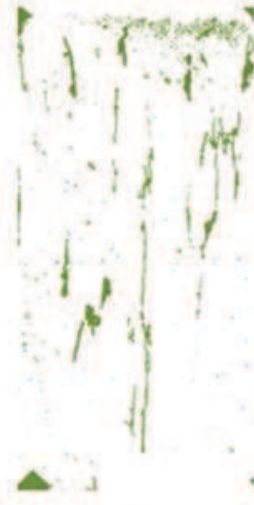

b

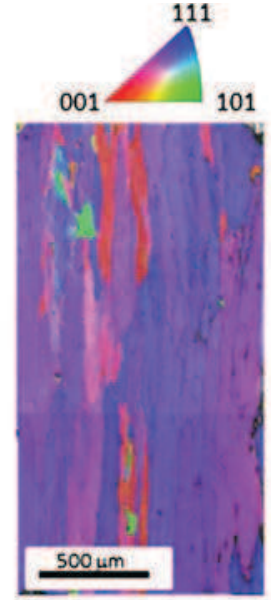

c

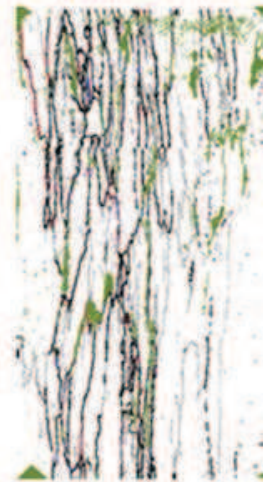

d

Fig. 9. Analysis of a NHT sample after a CI test in a well-identified zone. (a) SEM observation of the corrosion defect, backscattered electron image (b) 'corrosion map'; (c) IPFz0; (d) identification of the interfaces (grain boundaries in black or in color and subgrain boundaries in grey). (For interpretation of the references to color in this figure legend, the reader is referred to the web version of this article.)

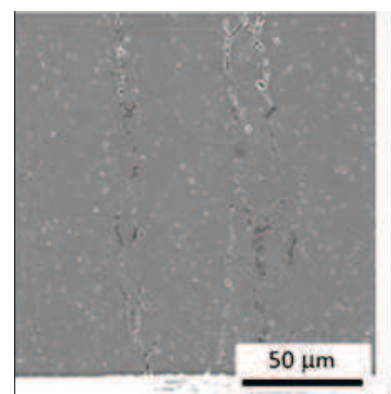

a

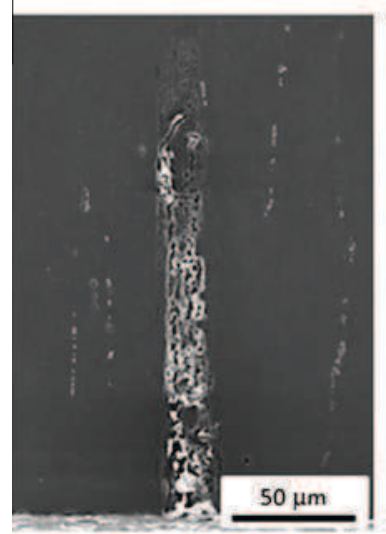

d

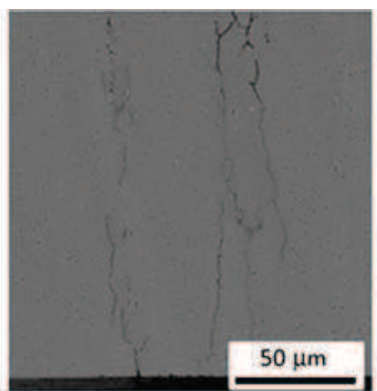

b

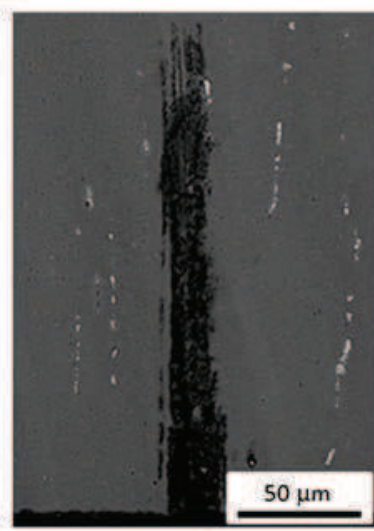

e
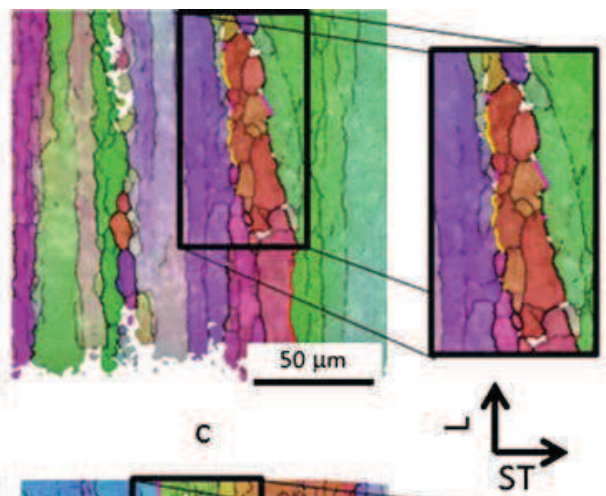

c

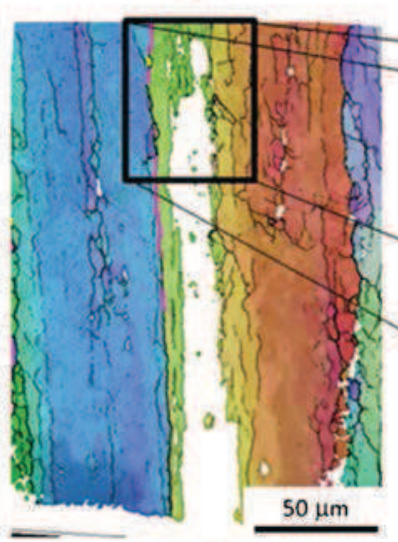

f

Fig. 10. SEM observations of (a), (b) NHT and (d), (e) HT samples after CR tests. (a) and (d) are secondary electron images; (b) and (e) are electron backscattered images. Superimposition of IPF-zo, identification of the interfaces and 'corrosion map' for (c) NHT and for (f) HT samples.

exposed to continuous immersion tests. However, corrosion at grain and/or subgrain boundaries was also observed in crosssections observed by SEM (Fig. 11b) but particularly for those cross-sections observed using EBSD (Fig. 11c). Further EBSD analysis, which was performed according to the methodology described in Fig. 9, confirmed that intragranular corrosion remained observed for HT samples after CR tests; however, a few grain boundaries and many subgrain boundaries were found to be corroded (Fig. 10d-f). This change in the corrosion morphology correlated with a lower propagation depth in the L direction for the corrosion defects after CR tests compared with $\mathrm{CI} 15 \mathrm{~h}$ and $\mathrm{CI}$ $72 \mathrm{~h}$ (Fig. 3d). However, similar to that for NHT samples, the linear density of the corrosion defects increased for CR tests (Fig. 3f). This evolution could be explained, similar to that for NHT samples, by the increase in the chloride concentration at the tip of the corrosion defects during the emersion period. Due to the increased aggressiveness of the electrolyte trapped inside the corrosion defects, new corrosion defects initiated, and the dissolution of 


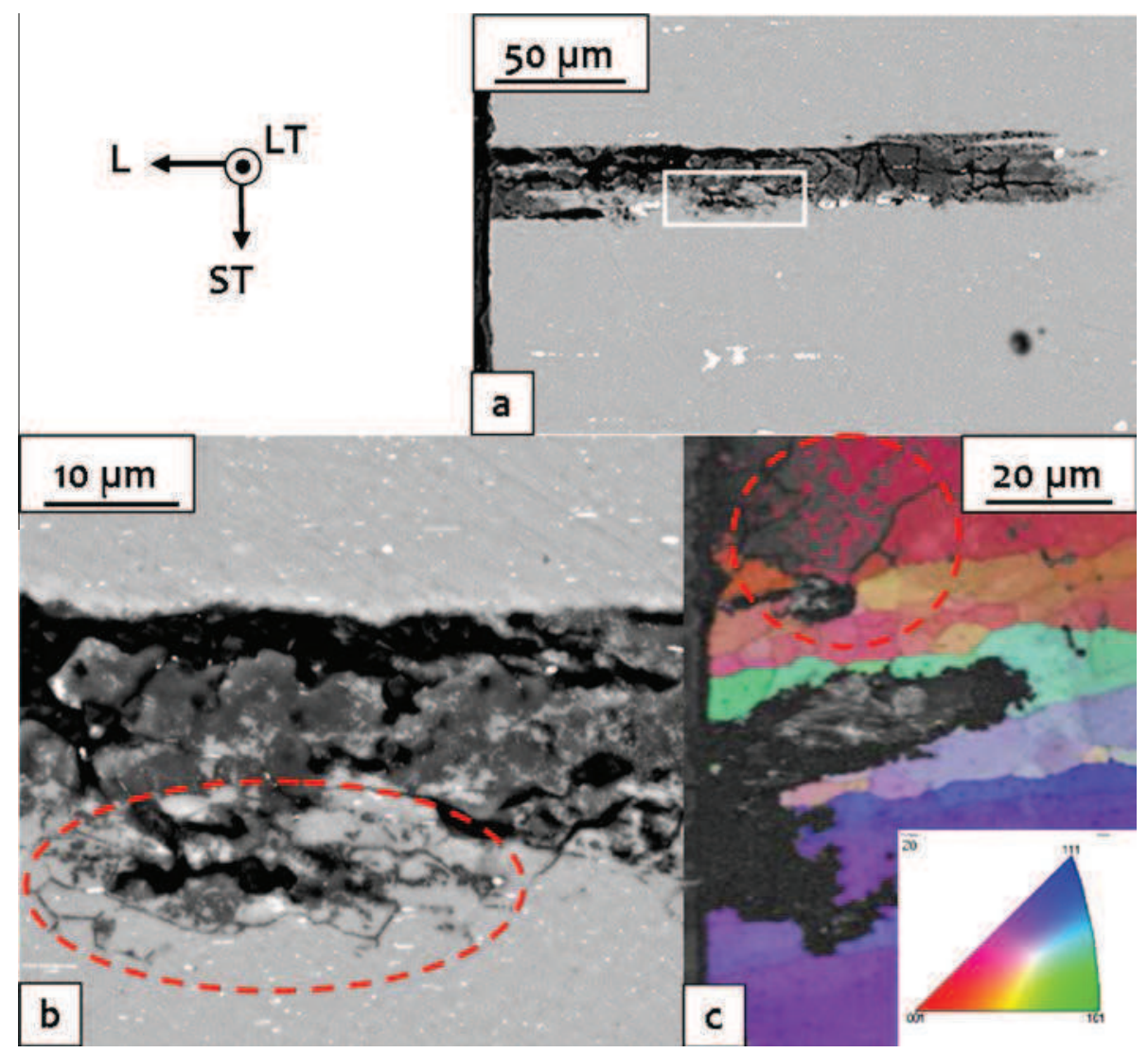

Fig. 11. HT sample after a CR test. (a) SEM observations of corrosion defects; (b) close-up on (a); (c) EBSD observations.

grain boundaries and subgrain boundaries also occurred. Concerning the lower propagation depth, this result might be explained by the interaction between intragranular corrosion defects and intergranular (grain boundaries and subgrain boundaries) defects; furthermore, as explained previously, statistical data must be carefully considered due to the difficulty in obtaining representative data with optical microscopy observations of corrosion defects.

To better describe the corrosion morphology after CR tests, tensile tests were performed after CR tests for both NHT and HT samples, and the results were compared with those results obtained after continuous immersion (Fig. 5a and Fig. 6a). Similar to that for continuous immersion tests, no shift in the flow stress was observed for NHT samples after CR tests compared with non-corroded samples, whereas a slight shift was observed for HT samples. As explained previously, this result could be explained by the morphology of the corrosion defects and by the loading direction during tensile tests. For NHT samples, intergranular defects generated during CR tests did not induce a non-load bearing zone; for HT samples after $\mathrm{CR}$ tests, defects are both intragranular and intergranular, which allow a non-load bearing zone to be generated. However, the shift in the flow stress is similar after CR tests compared with the shift observed after continuous immersion tests. This observation could be explained by the fact that the main difference in corrosion morphology between $\mathrm{CR}$ tests and continuous immersion for HT samples is the presence of the dissolution of grain boundaries and/or subgrain boundaries, whereas the evolution of intragranular defects is more complex and difficult to quantify, as mentioned above. Defects seem to be less deep but more numerous after CR tests compared with continuous immersion (Fig. 3). Furthermore, the shift in flow stress is clearly slight and the main result in Figs. 5a and 6a is the dramatic decrease in the elongation to failure for both NHT and HT samples after CR tests. In the literature, several authors also reported a decrease in the elongation to failure for corroded 2024 samples [20,24,26]. To explain this result, the authors assumed the occurrence of a volumetric phenomenon, i.e., hydrogen embrittlement, although this damaging phenomenon is rarely considered for 2 xxx alloys. In a study relative to $\mathrm{Al}-\mathrm{Li}$ alloys, it was assumed that the decrease in the ductility after corrosion tests could be attributed to a hydrogen embrittlement [32]. Generally, this hydrogen embrittlement preferentially affects the tensile strain capacities of metallic materials. Therefore, a ductility loss index was defined as $\left(A_{\text {non-corroded }}-\right.$ $\left.A_{\text {corroded }}\right) / A_{\text {non-corroded }}$, where $A_{\text {non-corroded }}$ is the elongation to failure for a non-corroded sample and $A_{\text {corroded }}$ is that of a corroded sample. Figs. 5b and 6b highlight a strong ductility loss index for both NHT and HT samples after CR tests compared with CI tests, suggesting a hydrogen effect. However, to consider the possible effect of hydrogen embrittlement as a volumetric effect, the corrosion layer should have been removed and then tensile specimens be constructed to differentiate the effect of corrosion from the effect of hydrogen on ductility. This was done by Kamoutsi et al. who clearly evidenced corrosion-induced hydrogen embrittlement in aluminum alloy 2024 [33,34]. In this work, to provide experimental evidence of hydrogen embrittlement, hydrogen content measurements were performed for each corrosion test condition for both NHT and HT samples. Regarding the results summarized in Figs. 5c and 6c, clearly CR tests led to a higher hydrogen content than continuous immersion. It was worth noticing that corrosion products were removed before performing hydrogen measurements. Of course, it seems impossible to ensure the total removal of the corrosion products. However, as previously mentioned, the morphological description of corrosion defects (Fig. 3) for HT samples after CR tests did not differ enough from that after continuous 
immersion to justify a higher amount of corrosion products after $\mathrm{CR}$ tests. The results from tensile tests corroborated this assertion (Fig. 6a), with an identical shift in the flow stress after CR tests and after $\mathrm{CI}$ tests. Therefore, such high values of the hydrogen content suggested a significant penetration of hydrogen inside the material during CR tests (thus, the ductility loss index was called the hydrogen embrittlement index). Hydrogen was generated by the cathodic reduction of $\mathrm{H}^{+}$present inside the corrosion defects following the hydrolysis of the metallic cations produced by the anodic reaction. Then, hydrogen penetrated inside the material, and a hydrogen-affected zone was assumed to exist at the tip of the corrosion defects, which could explain the results of the tensile tests. The amount of hydrogen inside the material after the corrosion tests, i.e., the size of the hydrogen-affected zone, depended on not only the amount of hydrogen produced at the tip of the corrosion defects but also the fraction of the surface accessible for hydrogen penetration. Hydrogen trapping and transport by dislocations could also be helpful in explaining a high hydrogen content, as well as the presence of hydrogen traps. Regarding hydrogen trapping, Kamoutsi et al. showed, for a 2024 aluminum alloy, that hydrogen could be trapped at S-phase, vacancies and dislocations [34]. Meletis and Huang showed that $T_{1}$ facilitates hydrogen entry into the $\mathrm{Al}-\mathrm{Cu}-\mathrm{Li}$ alloys and that hydrogen could be trapped at $\mathrm{T}_{1}$ matrix interfaces [35]. For $\mathrm{Al}-\mathrm{Cu}-\mathrm{Li}-\mathrm{Zr}$ alloys, Smith and Scully identified several metallurgical hydrogen trapping states, i.e. solid solution lithium, $\delta^{\prime}$ phases, dislocations, $\mathrm{T}_{1}$ precipitates and high angle boundaries [17,18]. Furthermore, Meletis and Huang showed that hydrogen from the $\mathrm{T}_{1}$-matrix interface may be swept relatively easily by dislocations since the $T_{1}$ phase precipitates on $\{111\}$ planes which are the matrix slip planes [35]. The authors provided some indication in support of the hydrogen-enhanced dislocation mobility by the softening (lower ultimate tensile strength) that was exhibited by the hydrogenembrittled alloys. Zohdi and Meletis showed that, in the presence of a crack, hydrogen penetration in front of the crack tip can occur mainly by stress assisted diffusion and dislocation transport [36]. In the present work, for the NHT samples, the increase in the corrosion defect depths and densities after CR tests compared with continuous immersion tests could explain much hydrogen production at the tip of the corrosion defects. The presence of hydrogen inside the corroded samples could then be explained by stress assisted diffusion and dislocation transport as suggested by Zohdi and Meletis [36]. No hydrogen trapping at $\mathrm{T}_{1}$ was assumed because no $\mathrm{T}_{1}$ was observed in NHT alloys. For the HT alloys, hydrogen embrittlement was most likely associated with the occurrence of intergranular corrosion after CR tests. Indeed, during CR tests, it was assumed not only that the penetration of hydrogen was linked to a diffusion process but also that this penetration was promoted by a transport phenomenon due to the stress imposed by the corrosion products trapped inside the intergranular corrosion defects on the intergranular defect walls. It seemed irrelevant to propose a stress state favorable for the penetration of hydrogen in intragranular corrosion defects. Therefore, the hydrogen content in the alloy after the CR tests was linked to both the local stress state at the tip of the intergranular corrosion defects and the hydrogen volume produced inside the defects. For HT alloys, intergranular corrosion propagated from intragranular defects after CR tests; intragranular corrosion was associated with a significant dissolution rate and, therefore, to high $\mathrm{H}^{+}$production. Therefore, the amount of hydrogen in the intergranular corrosion defects developed in HT samples after CR tests was most likely higher than that for NHT samples, explaining the higher amount of hydrogen in HT samples after CR tests compared with NHT samples. Furthermore, the high amount of $\mathrm{T}_{1}$ precipitates in HT samples could also explain the results because of hydrogen trapping at $T_{1}$ precipitates. To provide experimental evidence regarding hydrogen trapping at $T_{1}$ precipitates, desorption experiments were performed. NHT and HT samples were submitted to CI $72 \mathrm{~h}$ and CR $72 \mathrm{~h}$ tests. Immediately after the corrosion tests, the corrosion products were removed from the sample surface and the samples were submitted to desorption treatments. To take into account the discrepancy in the corrosion extent from one sample to another, only one sample was used for each corrosion test. The size of the samples was chosen so that they could be cut in several specimens. Each specimen was immediately submitted to a desorption treatment. The temperature for the desorption treatment was $25^{\circ} \mathrm{C}, 200^{\circ} \mathrm{C}, 340^{\circ} \mathrm{C}$ and $490^{\circ} \mathrm{C}$, as suggested by Smith and Scully $[17,18]$. The duration for the desorption treatment varied between $15 \mathrm{~min}$ and $24 \mathrm{~h}$. Immediately after the desorption treatment, the hydrogen content was measured. Results are reported in Fig. 12. For the NHT alloy, the results clearly showed that, for both $\mathrm{CI} 72 \mathrm{~h}$ and CR $72 \mathrm{~h}$, the hydrogen content decreased when the desorption temperature increased from $25^{\circ} \mathrm{C}$ to $490^{\circ} \mathrm{C}$. This showed that hydrogen desorption occurred and, therefore, that hydrogen was trapped inside the corroded material. Furthermore, independent of the desorption temperature, the hydrogen content was higher for the CR $72 \mathrm{~h}$ samples than for CI $72 \mathrm{~h}$ samples which was in good agreement with previous hydrogen content measurements (Fig. 5). However, except for the decrease of the hydrogen content when the desorption temperature increased from 25 to $490{ }^{\circ} \mathrm{C}$, no significant tendency was observed when hydrogen content versus desorption time for a given desorption temperature or hydrogen content versus desorption temperature for a given desorption time were plotted. For NHT alloy, hydrogen trapping at $\mathrm{T}_{1}$ precipitates did not occur because of the absence of $T_{1}$ in this metallurgical state. Hydrogen could then be trapped at dislocations or grain boundaries but with the methodology used, it was not possible to differentiate these trapping sites maybe due to the low hydrogen content compared to corrosion products that remained inside the corrosion defects. On the contrary, for HT samples, Fig. 12 clearly showed significant variation regarding the hydrogen content versus the temperature desorption and the hydrogen content versus desorption time. The tendency was the same for both $\mathrm{CI} 72 \mathrm{~h}$ and CR $72 \mathrm{~h}$ samples with, for all the desorption temperatures and all the desorption times, higher hydrogen contents for CR $72 \mathrm{~h}$ samples compared to $\mathrm{CI} 72 \mathrm{~h}$ samples in agreement with results shown in Fig 6. Differences between the results shown in Figs. 6 and 12 were related to the discrepancy in corrosion extent from one sample to another. As explained before, the desorption treatments were performed for the same corroded sample (cut in small pieces) to allow comparison between the different desorption times and temperatures. Independent of the desorption time, the hydrogen content progressively decreased when the desorption temperature increased from $25^{\circ} \mathrm{C}$ to $490{ }^{\circ} \mathrm{C}$ which allowed to reveal the different trapping sites identified by Smith and Scully $[17,18]$. Furthermore, for a long desorption time $(24 \mathrm{~h})$ at $490^{\circ} \mathrm{C}$, a significant decrease of the hydrogen content was observed, in particular for the $\mathrm{CR} 72 \mathrm{~h}$ samples. The hydrogen content reached a value around $20 \mathrm{ppm}$ corresponding to the hydrogen content measured for a non-corroded sample. Such a desorption treatment led to the release of hydrogen from $T_{1}$ precipitates showing that hydrogen trapping at $T_{1}$ precipitates was a major phenomenon for HT samples.

\subsection{Effect of the temperature during the emersion step of the cyclic corrosion tests on the corrosion susceptibility of the 2050 alloy}

To further analyze the effect of exposure conditions on the corrosion susceptibility of the 2050 alloy, additional cyclic corrosion tests were performed with emersion steps at a negative temperature (CF tests). For both NHT and HT samples, the morphology of the corrosion did not seem to be dependent on the temperature 

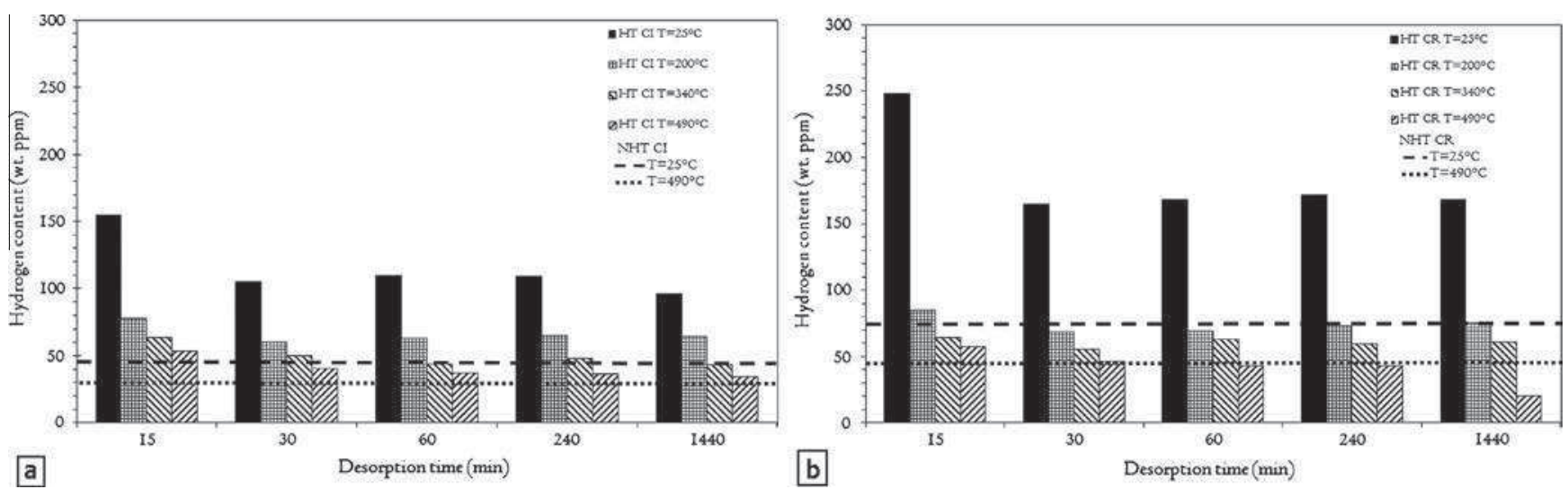

Fig. 12. Hydrogen content versus desorption time for desorption treatments at $25,200,340$ and $490{ }^{\circ} \mathrm{C}$. Results are given for corroded NHT and $\mathrm{HT}$ samples after (a) $\mathrm{CI} 72 \mathrm{~h}$ and (b) CR 72 h corrosion tests.

of the emersion phase. However, the decrease in the elongation to failure was lower after $\mathrm{CF}$ tests than after CR tests for both NHT (Fig. 5a and b) and HT samples (Fig. 6a and b). The results correlated well with a lower hydrogen content (Figs. 5c and $6 \mathrm{c}$ ) for $\mathrm{CF}$ samples compared with CR samples. Again, the amount of hydrogen present inside the material after the corrosion tests was partially explained by the kinetics of proton reduction inside the corrosion defects. For both NHT and HT samples, the statistical data (Fig. 3) concerning the morphology of the corrosion defects did not provide a reliable analysis of the kinetics of the aluminum dissolution and, therefore, of the proton reduction; a comparison of the data obtained after CR and CF tests showed that some morphological parameters increased, whereas other parameters decreased, from one exposure condition to another. However, one could assume that when the sample was emerged at room temperature, once the surface dried, the corrosion defects were the primary sites of electrochemical activity due the electrolyte trapped inside the corrosion defects. The main cathodic reaction was $\mathrm{H}^{+}$reduction, which explained the high hydrogen content measured for CR samples. In contrast, during emersion phases at negative temperatures, the electrolyte was frozen, and therefore, the electrochemical reactions were limited, leading to a lower hydrogen content after $\mathrm{CF}$ tests compared with CR tests. Furthermore, as previously explained, the hydrogen content inside the material after the corrosion tests could also be partially explained considering the surface, which allowed hydrogen penetration. During the emersion phase at negative temperatures, it can be assumed that the stress generated by the solidification of the electrolyte trapped inside the corrosion defects led to the local failure of the oxide film covering the walls of the corrosion defects, leading to an oxide layer less protective than the layer developed at room temperature [37]. This hypothesis was corroborated by electrochemical measurements performed for both NHT and HT samples at the beginning and at the end of each immersion period for CR and CF tests. Because the shape of the impedance diagrams was the same for all the measurements, only the diagrams plotted after $48 \mathrm{~h}$ of cyclic corrosion tests were plotted for CR (Fig. 13a) and CF (Fig. 13b) tests respectively. For the two alloys and for the two corrosion tests, the shape of the impedance diagrams was similar to that observed during $\mathrm{CI}$ tests with two time constants; therefore the same analysis was performed by extrapolating the $R_{t}$ value from the capacitive loop. For both CR and CF samples, and for both NHT and HT samples, $R_{t}$ decreased during immersion, revealing the degradation of the samples (Fig. 13c and d). However, during each emersion phase at room temperature (Fig. 13c), $R_{t}$ increased. This observation corresponded to an artificial healing phenomenon due to the formation of an oxide film on the sample surface during the air exposure and to the accumulation of corrosion products inside the corrosion defects. In contrast, the continuous decrease of $R_{t}$ for CF samples (Fig. 13d) suggested a defective oxide layer, as previously proposed, which could be related to the high linear density of corrosion defects (Fig. $3 \mathrm{c}$ and f), despite questions concerning the reliability of such data. Notably, the amplitude of the variations for the $R_{t}$ values was higher for NHT samples compared with HT samples; in particular, for HT samples and CF tests, $R_{t}$ only slightly varied during the entire duration of the test. The OCP measurements confirmed these results. Fig. 14 shows the evolution of the OCP during continuous immersion and during each immersion phase of CR and CF tests for both NHT (Fig. 14a) and HT alloys (Fig. 14b). For the NHT alloy, the OCP continuously decreased during continuous immersion, whereas for cyclic corrosion tests, the variation in the OCP was more complex (Fig. 14a). Considering the entire duration of the corrosion tests, the OCP globally decreased for both CR and CF tests, with a stronger decrease for $\mathrm{CF}$ tests. Examining the variations during each step of the corrosion tests, the OCP decreased during the immersion period; however, after each air exposure, the potential recovered to a value close to the potential value at the beginning of the corrosion test. The growth of an oxide layer on the alloy surface or the accumulation of corrosion products inside the corrosion defects during the emersion phase could be perceived as a healing of the corroded surface and could explain this result. However, the artificial healing of the oxide layer quickly disappeared during $\mathrm{CF}$ tests, as shown by the OCP decrease during the immersion period, which confirmed that the oxide layer was defective. In contrast, the OCP slightly dropped during the immersion period for $\mathrm{CR}$ tests, showing a more efficient healing phenomenon and a more protective oxide layer. Therefore, for NHT samples, the results showed that emersion periods at a negative temperature significantly influenced the properties of the oxide layer on the sample surface and inside the corrosion defects. Due to the stress developed by the electrolyte solidification trapped inside the intergranular corrosion defects during the emersion periods, the oxide layer was defective, which allowed hydrogen penetration. The increase in the surface, which allowed hydrogen penetration, compensated the reduced amount of hydrogen produced during CF tests compared with CR tests, which explained the slight differences in the hydrogen content between $\mathrm{CF}$ and $\mathrm{CR}$ samples. For HT samples, the OCP variations during the cyclic corrosion tests were extremely low, which could be related to the highly stable $\mathrm{OCP}$ measured during continuous immersion tests. This result was consistent with the impedance measurements and with the low amplitude of the variations in the $R_{t}$ values. Such a behavior could be explained by the corrosion morphology. For HT samples, during the emersion period at 

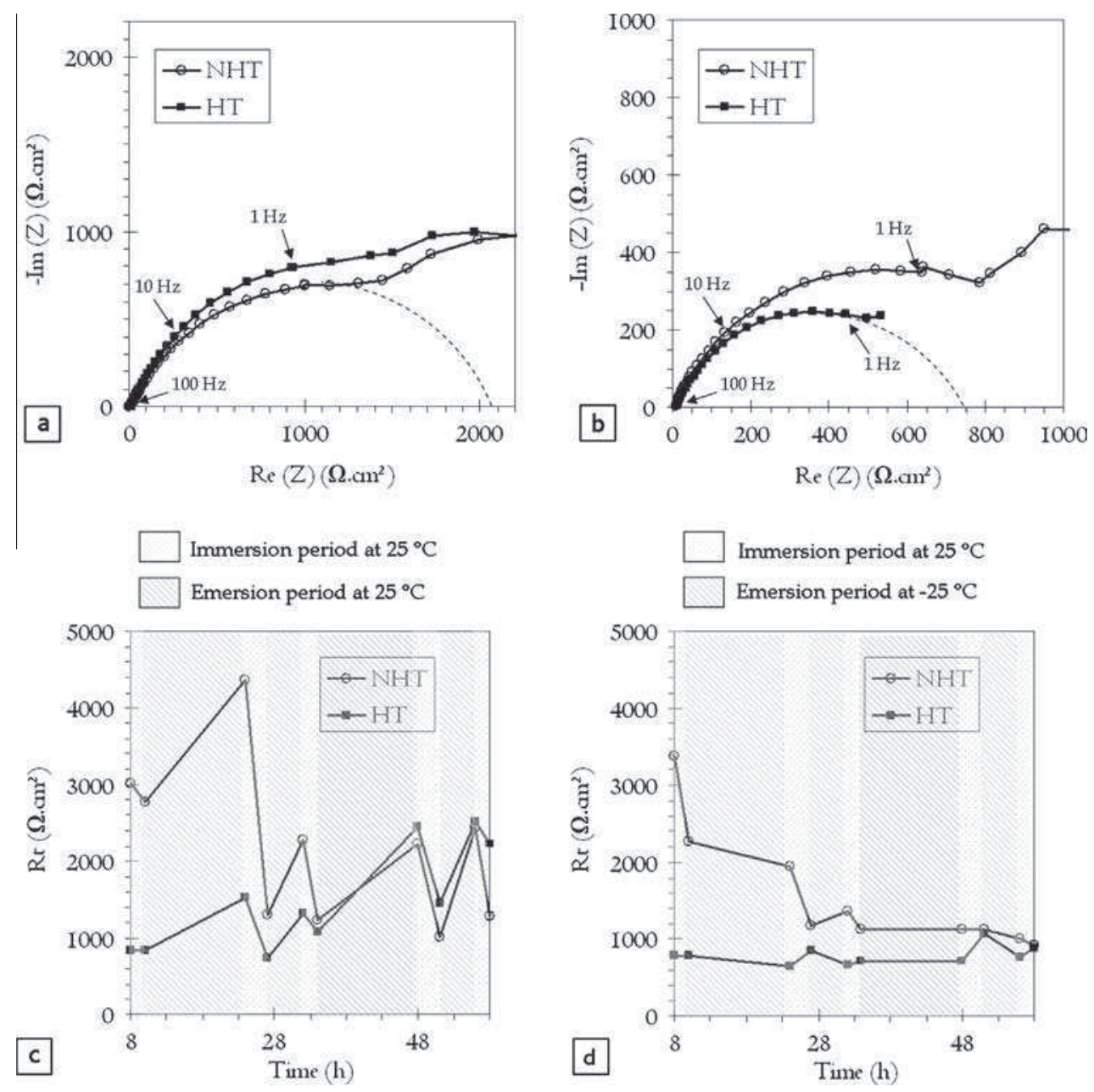

Fig. 13. Impedance diagrams (Nyquist plots) plotted at the beginning of the 5 th immersion period of cyclic corrosion tests (48 $\mathrm{h}$ after the beginning of the cyclic corrosion test) for NHT and HT alloys (a) CR sample; (b) CF sample. $R_{t}$ versus time for NHT and HT alloys for (c) CR samples and (d) CF samples.
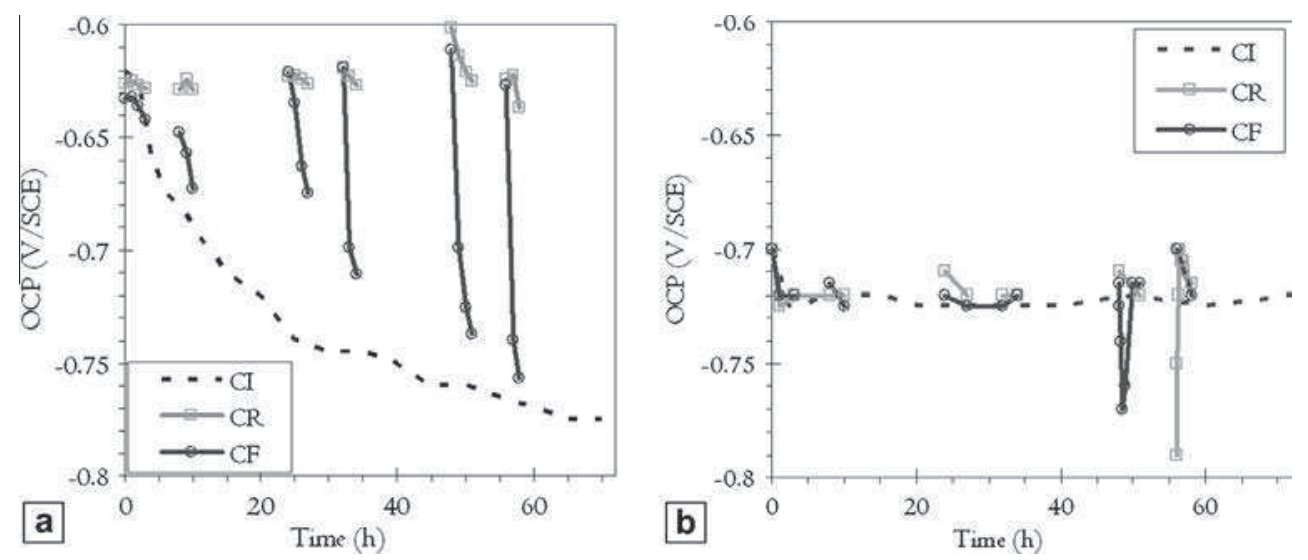

Fig. 14. Evolution of the open circuit potential (OCP) as a function of immersion time for $\mathrm{CI}, \mathrm{CR}$ and $\mathrm{CF}$ tests (for cyclic corrosion tests, $\mathrm{OCP}$ is recorded during the immersion periods). (a) NHT sample; (b) HT sample.

negative temperatures for $\mathrm{CF}$ tests, the solidification of the electrolyte and the resulting volume increase could not generate a stress state, which allowed a significant failure of the oxide layer, considering the morphology of the corrosion defects, i.e., intragranular defects with a high curvature radius. Therefore, for HT samples during $\mathrm{CF}$ tests, the amount of hydrogen produced was reduced compared with CR tests, and the effect of the electrolyte solidification was insufficient to increase the surface, allowing the hydrogen penetration. Thus, the difference in the hydrogen content between $\mathrm{CR}$ and $\mathrm{CF}$ tests was strong.

\section{Conclusions}

The corrosion behavior of the 2050 alloy was studied according to its microstructure and considering the influence of varying 
conditions of exposure to an aggressive environment. The main conclusions are as follows:

1. NHT and HT states differ by distinctive corrosion morphologies, intergranular and intragranular corrosion, respectively, during continuous immersion tests. Their corrosion behavior is linked to the presence of $\mathrm{T}_{1}$ hardening phases; however, the results showed that the presence of $\mathrm{T}_{1}$ precipitates is not mandatory for sensibilizing the 2050 alloy to intergranular corrosion.

2. The corrosion susceptibility of the 2050 alloy is strongly dependent on the condition of the exposure to an aggressive medium. The morphology, corrosion extension, and, consequently, the residual mechanical properties of corroded samples are significantly influenced by the exposure conditions. The main results are the extension of corrosion from grain boundaries to subgrain boundaries for the NHT alloy and the sensitization to intergranular corrosion for the HT alloy when cyclic corrosion tests were performed. The results suggest a hydrogen effect.

3. Depending on the morphology of the corrosion, i.e., intergranular or intragranular corrosion, therefore, depending on the microstructural state of the 2050 alloy, the hydrogen effect can play a predominant role in the corrosion process. The amount of hydrogen trapped inside the material primarily depends on three parameters: (i) the amount of hydrogen produced during the corrosion processes, which is linked to the morphology of the corrosion; (ii) the surface allowing hydrogen penetration inside the material. Surfaces for hydrogen entrance are created by the failure of oxide films developed on the corrosion defects walls. This failure is promoted by the solidification of the electrolyte trapped inside the intergranular corrosion defects during the emersion period at a negative temperature for cyclic corrosion tests; and (iii) the density of hydrogen traps inside the material, with $T_{1}$ precipitates as efficient traps.

4. The temperature during the emersion periods for cyclic corrosion tests plays a significant role in the corrosion susceptibility of the 2050 alloy. Negative temperatures could induce the failure of the oxide film due to a volume increase in the electrolyte trapped inside the corrosion defects and therefore promoted hydrogen penetration. However, negative temperatures stopped the electrochemical processes and therefore decreased the amount of hydrogen produced inside the corrosion defects. The corrosion susceptibility of the 2050 alloy results from the competition between these two phenomena.

\section{Acknowledgments}

This work was financially supported by the "Conseil Régional de la Région Midi-Pyrénées". The authors thank Constellium for the material supplied and M.-C. Lafont for TEM observations. The authors thank Nadine Pébère for fruitful discussions about electrochemical impedance spectroscopy measurements.

\section{References}

[1] E.J. Lavernia, N.J. Grant, Aluminium-lithium alloys, J. Mater. Sci. 22 (1987) $1521-1529$.

[2] V.K. Jain, K.V. Jata, R.J. Rioja, J.T. Morgan, A.K. Hopkins, Processing of an experimental aluminium-lithium alloy for controlled microstructure, J. Mater. Process. Technol. 73 (1998) 108-118.

[3] R.J. Rioja, J. Liu, Evolution of Al-Li base products for aerospace and space applications, Metall. Mater. Trans. A 43A (2012) 3325-3337.
[4] J.E. Kertz, P.I. Gouma, R.G. Buchheit, Localized corrosion susceptibility of Al-Li$\mathrm{Cu}-\mathrm{Mg}-\mathrm{Zn}$ alloy $\mathrm{AF} / \mathrm{C} 458$ due to interrupted quenching from solutionizing temperatures, Metall. Mater. Trans. A 33 (2001) 2561-2573.

[5] N. Jiang, J.F. Li, Z.Q. Zheng, Effect of aging on mechanical properties and localized corrosion behavior of Al-Cu-Li alloy, Trans. Nonferr. Met. Soc. China 15 (2005) 23-29.

[6] H.Y. Li, Y. Tang, Z.D. Zeng, F. Zheng, Exfoliation corrosion of T6- and T3-aged AlxCuyLiz alloy, Trans. Nonferr. Mater. Soc. of China 18 (2008) 778-783.

[7] V. Proton, J. Alexis, E. Andrieu, C. Blanc, J. Delfosse, L. Lacroix, G. Odemer, Influence of post-welding heat treatment on the corrosion behavior of a 2050 T3 aluminum-copper-lithium alloy friction stir welding joint, J. Electrochem. Soc. 158 (2011) C139-C147.

[8] Y. Xu, X. Wang, Z. Yan, J. Li, Corrosion properties of light-weight and highstrength 2168 Al-Li alloy, Chin. J. Aeronaut. 24 (2011) 681-686.

[9] R.G. Buchheit, J.P. Moran, G.E. Stoner, Localized corrosion behavior of alloy 2090-the role of microstructure heterogeneity, Corrosion 46 (1990) 610-617.

[10] R. Scully, T.O. Knight, R.G. Buchheit, D.E. Peebles, Electrochemical characteristics of $\mathrm{Al}_{2} \mathrm{Cu}, \mathrm{Al}_{3} \mathrm{Ta}$ and intermetallics phases and their relevancy to the localized corrosion of Al, Corros. Sci. 35 (1993) 185-195.

[11] F. Viejo, A.E. Coy, F.J. Garcia-Garcia, Z. Liu, P. Skeldon, G.E. Thompson, Relationship between microstructure and corrosion performance of AA2050T3 aluminium alloy after excimer laser surface melting, Corros. Sci. 52 (2010) 2179-2187.

[12] H. Amar, V. Vignal, H. Krawiec, C. Josse, P. Peyre, S.N. Da Silva, L.F. Dick, Influence of the microstructure and laser shock processing (LSP) on the corrosion behaviour of the AA2050-T3 aluminium alloy, Corros. Sci. 53 (2011) 3215-3221.

[13] R.G. Buchheit, J.P. Moran, G.E. Stoner, Electrochemical behavior of $\mathrm{T}_{1}\left(\mathrm{Al}_{2} \mathrm{CuLi}\right)$ intermetallic compound and its role in localized corrosion of $\mathrm{Al}-2 \% \mathrm{Li}-3 \% \mathrm{Cu}$ alloys, Corrosion 50 (1994) 120-130.

[14] J.F. Li, Z.Q. Zheng, N. Jiang, S.C. Li, Study on localized corrosion mechanism of $2195 \mathrm{Al}-\mathrm{Li}$ alloy in $4.0 \% \mathrm{NaCl}$ solution ( $\mathrm{pH}$ 6.5) using a three-electrode coupling system, Mater. Corros. 56 (2005) 192-196.

[15] J.F. Li, C.X. Li, Z.W. Peng, W.J. Chen, Z.O. Zheng, Corrosion mechanism associated with $\mathrm{T} 1$ and $\mathrm{T} 2$ precipitates of $\mathrm{Al}-\mathrm{Cu}-\mathrm{Li}$ alloys in $\mathrm{NaCl}$ solution, J. Alloys Compd. 460 (2008) 688-693.

[16] F. Viejo, Z. Aburas, A.E. Coy, F.J. Garcia-Garcia, Z. Liu, P. Skeldon, Performance of Al alloys following excimer LSM-anodising approaches, Surf. Interface Anal. 42 (2010) 252-257.

[17] S.W. Smith, J.R. Scully, Hydrogen trapping and its correlation to the hydrogen embrittlement susceptibility of Al-Li-Cu-Zr Alloys, in: A.W. Thompson, N.R. Moody (Eds.), Hydrogen Effects in Materials (Fifth International Conference): TMS, 1994, pp. 131-141.

[18] S.W. Smith, J.R. Scully, Identification of hydrogen trapping states in an Al-Li$\mathrm{Cu}-\mathrm{Zr}$ alloy using thermal desorption spectroscopy, Metall. Mat. Trans. A: Phys. Metall. Mater. Sci. 31 (2000) 179-193.

[19] R.P. Vera Cruz, A. Nishikita, T. Tsuru, Corrosion mechanism of stainless steels under wet \& dry exposure, Corros. Sci. 40 (1998) 125-139.

[20] Sp.G. Pantelakis, P.G. Daglaras, Ch.Alk. Apostolopoulos, Tensile and energy density properties of 2024, 6013, 8090 and 2091 aircraft aluminium alloy after corrosion exposure, Theor. Appl. Fract. Mech. 33 (2000) 117-134.

[21] G.A. El-Mahdy, K.B. Kim, AC impedance study on the atmospheric corrosion of aluminum under periodic wet-dry conditions, Electrochim. Acta 49 (2004) 1937-1948.

[22] A.P. Yadav, A. Nishikita, T. Tsuru, Electrochemical impedance study on galvanized steel corrosion under cyclic wet-dry conditions-influence of time of wetness, Corros. Sci. 46 (2004) 169-181.

[23] M.-C. Zhao, P. Schmutz, S. Brunner, M. Liu, G.-L. Song, A. Atrens, An exploratory study of the corrosion of $\mathrm{Mg}$ alloys during interrupted salt spray testing, Corros. Sci. 51 (2009) 1277-1292.

[24] C. Larignon, J. Alexis, E. Andrieu, C. Blanc, G. Odemer, J.-C. Salabura, Corrosion damages induced by cyclic exposure of 2024 aluminum alloy in chloridecontaining environments, J. Electrochem. Soc. 158 (2011) 284-295.

[25] V. Proton, J. Alexis, E. Andrieu, J. Delfosse, A. Deschamps, F. De Geuser, M.-C. Lafont, C. Blanc, The influence of artificial ageing on the corrosion behaviour of a 2050 aluminium-copper-lithium alloy, Corros. Sci. 80 (2014) 494-502.

[26] C. Augustin, E. Andrieu, C. Blanc, J. Delfosse, G. Odemer, Empirical propagation laws of intergranular corrosion defects affecting 2024 T351 alloy in chloride solutions, J. Electrochem. Soc. 157 (2010) 428-436.

[27] R.E. Lobnig, D.J. Siconolfi, J. Maisano, G. Grundmeier, H. Streckel, R.P. Frankenthal, M. Stratmann, J.D. Sinclair, Atmospheric corrosion of aluminum in the presence of ammonium sulfate particles, J. Electrochem. Soc. 143 (1996) $1175-1182$.

[28] T. Hagyard, W.B. Earl, K.J. Kirkpatrick, I.G. Watson, The electrode potential of evaporated aluminum films in chloride solution, J. Electrochem. Soc. 113 (1966) 962-963.

[29] T. Hagyard, W.B. Earl, Potential of aluminum in aqueous chloride solutions, J. Electrochem. Soc. 114 (1967) 694-698.

[30] M. Keddam, C. Kuntz, H. Takenouti, D. Schuster, D. Zuili, Exfoliation corrosion of aluminium alloys examined by electrode impedance, Electrochim. Acta 42 (1997) 87-97.

[31] J.Tedim, M.L. Zheludkevich, A.C. Bastos, A.N. Salak, A.D. Lisenkov, M.G.S. Ferreira, Influence of preparation conditions of layered double hydroxide conversion films on corrosion protection, Electrochim. Acta 117 (2014) 164-171. 
[32] Sp.G. Pantelakis, N.I. Vassilas, P.G. Daglaras, Effects of corrosive environmen on the mechanical behaviour of the advanced Al-Li alloys 2091 and 8090 and the conventional aerospace alloy 2024, Metallurgy 47 (1993) 135-141.

[33] H. Kamoutsi, G.N. Haidemenopoulos, V. Bontozoglou, S. Pantelakis, Corrosion induced hydrogen embrittlement in aluminum alloy 2024, Corros. Sci. 48 (2006) 1209-1224.

[34] H. Kamoutsi, G.N. Haidemenopoulos, V. Bontozoglou, P.V. Petroyiannis, S. Pantelakis, Effect of prior deformation and heat treatment on the corrosioninduced hydrogen embrittlement in aluminum alloy 2024, Corros. Sci. 80 (2014) 139-142.
[35] E.I. Meletis, W. Huang, The role of the $T_{1}$ phase in the pre-exposure and hydrogen embrittlement of Al-Li-Cu alloys, Mater. Sci. Eng. A 148 (1991) hydrogen

[36] T.I. Zohdi, E.I. Meletis, On the intergranular hydrogen embrittlement mechanism of Al-Li alloys, Scripta Metall. Mater. 26 (1992) 1615-1620.

[37] C. Larignon, J. Alexis, E. Andrieu, G. Odemer, C. Blanc, The contribution of hydrogen to the corrosion of 2024 aluminium alloy exposed to thermal and environmental cycling in chloride media, Corros. Sci. 69 (2013) 211-220. 